\title{
Differential Effects of Monocular Deprivation on Glutamic Acid Decarboxylase and Type II Calcium-Calmodulin-Dependent Protein Kinase Gene Expression in the Adult Monkey Visual Cortex
}

\author{
D. L. Benson, ${ }^{1}$ P. J. Isackson, ${ }^{1,2}$ C. M. Gall, ${ }^{1}$ and E. G. Jones' \\ 'Department of Anatomy and Neurobiology and 2Department of Biological Chemistry, University of California, Irvine, \\ California 92717
}

\begin{abstract}
Increases in immunocytochemically detectable type II calcium-calmodulin-dependent protein kinase (CaM II kinase) and decreases in immunocytochemically detectable glutamic acid decarboxylase (GAD) are known to occur in the visual cortex of adult monkeys following brief periods of monocular visual deprivation. In the present study, GAD and CaM II kinase gene expression was investigated under these conditions. The polymerase chain reaction (PCR) was used to generate species-specific cDNA clones that were used to make antisense RNA probes. A second form of CaM II kinase $\alpha$, CaM II kinase $\alpha-33$, which contains an additional phosphorylation consensus sequence, was identified. In situ hybridization in normal visual cortex revealed a complex sublaminar organization of GAD-expressing cells within layers IVC and VI and a distribution of CaM II kinase $\alpha$-expressing cells that was greatest in layers II, III, IVB, and VI. In situ hybridization in the cortex from animals that had been monocularly deprived revealed enhanced CaM II kinase mRNA levels in deprived-eye columns of layer IVC and, associated with the deprived eye, cytochrome oxidase-stained periodicities in other layers. In layer IV, the enhancement of labeling in deprived-eye stripes was, on average, $16 \%$ greater than in normal-eye stripes. By contrast, GAD mRNA levels appeared unchanged in all layers, suggesting a posttranscriptional regulatory mechanism.
\end{abstract}

Neural activity appears to play an important role in the regulation of gene expression for numerous neuroactive molecules. In the PNS, studies of autonomic ganglia and the adrenal medulla show that depolarization-dependent events regulate levels of mRNAs for enzymes involved in catecholamine transmitter synthesis and for the precursors of certain neuropeptides (Kessler and Black, 1982; Kilpatrick et al., 1984; LaGamma et al., 1984; Black et al., 1985; Kanamatsu et al., 1986b; Roach et al., 1987; La Gamma and Black, 1989). In the CNS, recurrent epileptiform activity leads to selective changes in mRNA levels for certain neuropeptides (Kanamatsu et al., 1986a; Morris et al., 1987; White et al., 1987; Gall et al., 1990) and growth factors

Received May 9, 1990; revised July 24, 1990; accepted Aug. 30, 1990

We thank Molly Huntsman for expert technical assistance and Dr. S. H. C. Hendry for advice and assistance. This work was supported by Grants EY-07193 and NS26748 from the NIH, U.S. Public Health Service and by the Irvine Research Unit in Molecular Neurobiology.

Correspondence should be addressed to Dr. E. G. Jones, Department of Anatomy and Neurobiology, University of California, Irvine, CA 92717.

Copyright (C) 1991 Society for Neuroscience 0270-6474/91/010031-17\$03.00/0
(Gall and Isackson, 1989), and enhanced neural activity can stimulate increases in the abundance of mRNAs that encode known and putative transcription activation factors (Morgan et al., 1987; White and Gall, 1987; Sagar et al., 1988; Cole et al., 1989).

Neural activity also exercises a powerful influence over the development of the nervous system (Harris, 1981), during the course of which, major changes in gene expression can be expected to occur. In the CNS of primates, activity-dependent, developmental changes have been especially studied in the visual cortex of monkeys. Anatomical and physiological plasticity can be induced in the monkey visual cortex by perturbed visual experience during a critical period in the first few months of life (Hubel and Wiesel, 1977; Hubel et al., 1977; LeVay et al., 1980), and certain effects may be seen into the second year (Blakemore et al., 1978). In adult monkeys, retinal activity continues to exert a strong influence over the visual cortex. In these animals, brief periods of monocular deprivation brought about by eye removal, or by action potential blockade via intraocular tetrodotoxin (TTX) injections, and lasting for as little as $2 \mathrm{~d}$ will lead, in the deprived-eye columns of the visual cortex, to reductions in levels of immunocytochemically detectable GABA, its synthesizing enzyme, glutamic acid decarboxylase (GAD), the $\mathrm{GABA}_{\mathrm{A}}$ receptor, and certain tachykinins (Hendry and Jones, 1986; Hendry et al., 1988, 1990). Over the same time course, immunocytochemically detectable levels of type II calciumcalmodulin-dependent protein kinase (CaM II kinase) increase in the deprived-eye columns (Hendry and Kennedy, 1986). The GABA/GAD effect, at least, is rapidly reversible, and the maintenance of normal levels of these molecules depends upon the maintenance of action potentials in the optic nerve (Hendry and Jones, 1988). These changes in protein and transmitter content indicate that afferent activity not only regulates transmitter and receptor function in the adult visual cortex, but also controls levels of second-messenger-related phosphoproteins that can be expected to have long-term effects on neuronal function (Malenka et al., 1989; Malinow et al., 1989).

The results of studies on activity-dependent regulation of gene expression in other systems suggest that activity-dependent upor down-regulation of the relevant genes might underlie the changes in immunocytochemically detected protein levels demonstrable in the deprived visual cortex of adult primates. In the present study, therefore, the regulation of CaM II kinase and GAD transcription under conditions of monocular deprivation was investigated by cDNA analysis and in situ hybridization. 
Preliminary reports have appeared (Benson et al., 1988, 1989b).

\section{Materials and Methods}

Oligonucleotide preparation for $P C R$. To amplify specifically GAD and CaM II kinase cDNAs derived from monkey messenger RNA, synthetic oligonucleotide primers were made that corresponded to regions likely to be conserved between known species.

The 2 oligonucleotides synthesized for GAD polymerase chain reaction (PCR) amplification each contained 21 bases of sequence that are identical in cat GAD cDNA (Kobayashi et al., 1987) and human GAD cDNA (D.L. Benson, unpublished observations). The $5^{\prime}$ sensestrand oligonucleotide ( $5^{\prime}$-GGATCCCCTCACAAGATGATGGGCGTG- $3^{\prime}$ ) contains a BamHI site and 21 bases corresponding to bases 1324-1344 of cat GAD cDNA (Kobayashi et al., 1987). This region encompasses the sequence encoding the pyridoxal phosphate-binding region. The $3^{\prime}$ antisense oligonucleotide (5'-GAGGCTTTGTGGAATATACCA-3') contains 21 bases corresponding to bases 1663-1683 of cat GAD cDNA. An EcoRI linker was ligated to the amplified fragment.

A species comparison of CaM II kinase cDNAs was not possible because the kinase has been sequenced only in the rat (Bennett and Kennedy, 1987; Lin et al., 1987). However, the sequences for all 3 subunits that comprise the enzyme $\left(\alpha, \beta\right.$, and $\left.\beta^{\prime}\right)$ in the rat demonstrate regions of great similarity that were exploited to generate oligonucleotides (Bulleit et al., 1988).

The 2 oligonucleotides synthesized for CaM II kinase analysis were chosen such that they would flank the region of greatest subunit variability. The $5^{\prime}$ sense-strand CaM II kinase oligonucleotide (5'GGATCCCTGAAGAAGTTCAATGCCAGG-3') sequence contains a BamHI site and 21 bases of sequence corresponding to bases 869-889 of the $\alpha$ subunit rat cDNA (Lin et al., 1987). This segment is $95 \%$ identical in the $\alpha, \beta$, and $\beta^{\prime}$ subunits and lies entirely within the highly conserved kinase domain. The $3^{\prime}$ antisense oligonucleotide (5'-GTCGACATGAAAGTCCAGGCCCTCGAC- $3^{\prime}$ ) contains a Sall site and 21 bases of sequence (bases 1 165-1185 of the $\alpha$ subunit) from a moderately conserved region ( $76 \%$ identical) downstream from the variable region (Fig. 1).

Generating $c D N A$ clones. Total RNA was extracted from monkey visual cortex (GAD) or frontal cortex (CaM II kinase) using the method of Chirgwin et al. (1979). Ten $\mu \mathrm{g}$ RNA was primed with oligo-dT and reverse transcribed with avian myeloblastosis virus reverse transcriptase (Boehringer Mannheim Biochemicals). One half of the resultant singlestranded cDNA was subjected to 35 cycles of PCR amplification as described by Saiki et al. $(1985,1988)$.

Amplified cDNA was restricted with either BamHI and EcoRI (GAD) or BamHI and SalI (CaM II kinase), purified by electroelution from a polyacrylamide gel and ligated to BamHI/EcoRI- or BamHI/SalI-digested pBluescribe (pBS; Stratagene), and transformed into 71.18 cells. Plasmids containing inserts were sequenced by the dideoxy-chain-termination method with modified bacteriophage T7 DNA polymerase (Sanger et al., 1977; Tabor and Richardson, 1987).

Labeling probes. For an antisense GAD riboprobe, the pBSGAD clone was linearized with either BamHI or PvuII and transcribed with T7 RNA polymerase. The former restriction was used to create a 365 nucleotide antisense riboprobe for in situ hybridization, and the latter restriction encoded a run-off transcript of 615 nucleotides for S1 endonuclease protection assays. Riboprobes were transcription labeled with $\alpha-{ }^{35} \mathrm{~S}-\mathrm{UTP}$ for in situ hybridization preparations and with $\alpha-{ }^{32} \mathrm{P}$ UTP for S1 nuclease protection experiments. Sense-strand control riboprobes for in situ hybridization were transcribed from PvuII-digested pBSGAD using T3 RNA polymerase

CaM II kinase antisense riboprobes were transcribed with T3 RNA polymerase from BamHI- or PvuII-restricted pBSCKII $\alpha-33$. The BamHI-digested plasmid yielded a 373-nucleotide riboprobe that was labeled with $\alpha-{ }^{35}$ S-UTP, and the PvuII-cut plasmid yielded a 517-nucleotide riboprobe labeled with $\alpha{ }^{32}$ P-UTP (Fig. 1). The Pvull-cut plasmid was transcribed with T7 RNA polymerase and labeled with $\alpha-{ }^{35} \mathrm{~S}$ UTP for sense-strand in situ hybridization controls.

Antisense cyclophilin was transcribed with T7 RNA polymerase from Pstl-digested p1B15 (Milner and Sutcliffe, 1983) and was labeled with $\alpha-{ }^{32} P-U T P$. This yields a transcript approximately 680 bases long. Cyclophilin hybridization was used as a control for the $\mathrm{S} 1$ nuclease protection experiments (Sutcliffe et al., 1983).

S1 nuclease protection assays. The primary visual cortex was removed from one hemisphere of 9 adult Macaca fuscata or Macaca fascicularis monkeys under ketamine and Nembutal anesthesia, and RNA was extracted according to the method of Chirgwin et al. (1979). All monkeys were $3 \mathrm{yr}$ old or older. Three were normal; 6 had been monocularly deprived for varying amounts of time $(2,5,7.5,24,48$, and $144 \mathrm{hr})$ : in the 5 surviving $2-48 \mathrm{hr}$, action potential activity was blocked in retinal ganglion cells by injecting $15 \mu \mathrm{g}$ of the sodium channel blocker TTX once in the vitreous chamber of 1 eye under ketamine anesthesia (Hendry and Jones, 1986). The efficacy of the TTX injections in blocking optic nerve activity was monitored by noting the continuing absence of direct and consensual light reflexes. In the one monkey surviving 144 $\mathrm{hr}$, an eye was removed by surgical enucleation under barbiturate anesthesia. Total RNA $(2.5 \mu \mathrm{g}), 50 \mu \mathrm{g}$ wheat germ tRNA, and an excess of ${ }^{32} \mathrm{P}$-labeled riboprobe were ethanol precipitated and resuspended in hybridization buffer containing $80 \%$ deionized formamide and incubated at $58^{\circ} \mathrm{C}$ for $12-15 \mathrm{hr}$. Following hybridization, remaining singlestranded RNA was digested with 200 U SI nuclease (Pharmacia) for 3 $\mathrm{hr}$ at $37^{\circ} \mathrm{C}$, then separated on $6 \%$ polyacrylamide, $7 \mathrm{M}$ urea gels (Berk and Sharp, 1977). Gels were exposed to Kodak XAR film for 1-3 d.

In situ hybridization. This portion of the study was carried out on the visual cortex from 10 adult macaque monkeys ( 7 Macaca fuscata, 2 Macaca fascicularis, 1 Macaca arctoides). They were aged from 3 to 20 yr. Two normal animals served as controls. Six animals were monocularly deprived for periods ranging from $48 \mathrm{hr}$ to $5 \mathrm{~d}$ by TTX injection into 1 eye as above; 2 of the animals that survived for 4 and $5 \mathrm{~d}$ were given a second TTX injection on the fourth day. In 1 animal, under ketamine anesthesia, the retinal ganglion cells were destroyed by a single intraocular injection of $0.3 \mathrm{ml} 100 \mathrm{~mm}$ cobalt chloride $15 \mathrm{~d}$ before death (see Malpeli and Schiller, 1979), and in the remaining animal, under barbiturate anesthesia, one eye was enucleated $5 \mathrm{~d}$ prior to death. Each of these methods, at the survival times used, in our hands have proven to be equally effective in producing immunocytochemically detectable changes in GAD and CaM II kinase. The efficacy of the TTX injections was monitored as above. Cobalt chloride injections in the dose given cause opthalmoscopically visible damage to the retina. The data presented are derived from all 3 types of deprivation. All animals were given an overdose of Nembutal and perfused transcardially with mixtures of paraformaldehyde $(2-4 \%)$, with or without glutaraldehyde $(0.1-0.2 \%)$. Best results for in situ hybridization were obtained with $4 \%$ paraformaldehyde in $0.05 \mathrm{~m}$ phosphate buffer $(\mathrm{pH}, 7.4)$. Brains were postfixed overnight in $4 \%$ paraformaldehyde and cryoprotected in $20 \%$ sucrose/ $4 \%$ paraformaldehyde.

Blocks were frozen on dry ice, and $25-\mu \mathrm{m}$ serial sections were cut on a sliding microtome in the frontal plane or in a plane parallel to the lateral surface of the occipital lobe and collected in groups of 5 in cold $0.1 \mathrm{~m}$ phosphate buffer. One section of each group was labeled with the antisense GAD probe, a second with the antisense $\mathrm{CaM}$ II kinase probe (see below), a third was stained with $0.25 \%$ thionin, and a fourth was stained for cytochrome oxidase (CO; Wong-Riley, 1979). The fifth was used for repeat series when necessary.

Free-floating sections were pretreated for in situ hybridization by successive incubations in $0.1 \mathrm{~m}$ glycine in $0.1 \mathrm{M}$ phosphate buffer $(\mathrm{pH}$, $7.2) ; 1 \mu \mathrm{g} / \mathrm{ml}$ proteinase $\mathrm{K}(\mathrm{pH}, 8)$ for $30 \mathrm{~min}$ at $30^{\circ} \mathrm{C} ; 0.25 \%$ acetic anhydride in $0.1 \mathrm{M}$ triethanolamine $(\mathrm{pH}, 8.0)$; and $2 \times$ saline sodium citrate (SSC). Following this, sections were incubated in the hybridization buffer containing $50 \%$ deionized formamide, $10 \%$ dextran sulfate, $0.7 \%$ Ficoll, $0.7 \%$ polyvinyl pyrolidone, $350 \mathrm{mg} / \mathrm{ml} \mathrm{BSA}, 0.15 \mathrm{mg} / \mathrm{ml}$ yeast tRNA, $0.33 \mathrm{mg} / \mathrm{ml}$ denatured herring sperm DNA, and $20 \mathrm{~mm}$ dithiothreitol (DTT) for $1 \mathrm{hr}$ at $60^{\circ} \mathrm{C}$, then transferred to fresh hybridization buffer containing an additional $20 \mathrm{~mm}$ DTT and $1 \times 10^{4} \mathrm{cpm} /$ $\mu \mathrm{l}$ of the ${ }^{35} \mathrm{~S}$ antisense riboprobe for at least $20 \mathrm{hr}$ at $60^{\circ} \mathrm{C}$ (Gall and Isackson, 1989).

Following hybridization, sections were washed in $4 \times$ SSC, digested with $20 \mu \mathrm{g} / \mathrm{ml}$ ribonuclease $\mathrm{A}(\mathrm{pH}, 8)$ for $30 \mathrm{~min}$ at $45^{\circ} \mathrm{C}$, and washed through descending concentrations of SSC with $5 \mathrm{~mm}$ DTT to a final stringency of $0.1 \times \mathrm{SSC}$ at $60^{\circ} \mathrm{C}$ for $1 \mathrm{hr}$. Sections were mounted onto gelatin-coated slides, dried, and exposed to Amersham $\beta$ max film for 1-4 d. Following development of the film, the sections were lipid extracted in chloroform, dipped in Kodak NTB2 emulsion diluted 1:1 with water, exposed for $7-15 \mathrm{~d}$ at $4^{\circ} \mathrm{C}$, developed in Kodak D19, fixed, and stained through the emulsion with cresyl violet. Film densitometry, as further described in the Results, was conducted with a microcomputer imaging device (Imaging Research). Each autoradiographic image was calibrated to ${ }^{14} \mathrm{C}$-labeled brain paste standards exposed on the same sheet of film.

Sense-strand radiolabeled RNA probes were hybridized to selected 
A
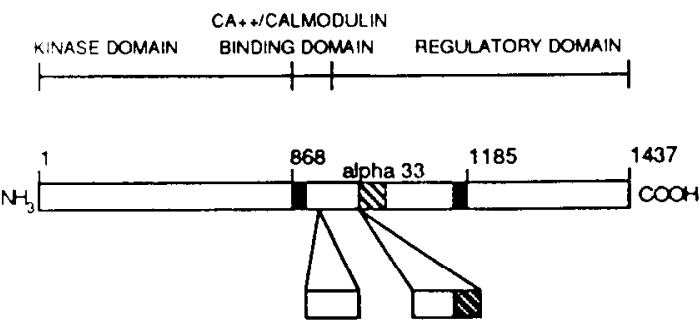

B subunit inserts

CALCIUM-CALMODULIN DEPENDENT PROTEIN KINASE TYPE II (a)

868 Leu Lys Lys Phe Asn Ala Arg Arg Lys Leu Lys Gly Ala De Leu thr rat CTGAAGAAG TTC AAT GCCAGG AGG AAA CTG AAG GGA GCC ATC CTC ACC

Thr Met Leu Ala Thr Arg Asn Phe Ser Gly Gly Lys Ser Giy Gly Asn rat ACT ATG CTG GCC ACC AGG AAC TTC TCC GGA GGG AAG AGT GGA GGA AAC mky AGC ATG CTG GCC ACC AGG AAC TTC TCC GGA GGG AAG AGT GGG GGA AAC

Ser

Lys Lys Asn Asp Gly Val Lys Lys CArr. Lys Ser Ser Ser. Ser Val mky AAG AAG AGC GAT GGT GTG AAG AAA AGA AAG TCC AGT TCC AGC GTT UY AAG AAG ACE

Gin Leu Met Glu Ser Ser Glu Ser Thr Asn Thr Thr lle Glu Asp Glu GAA TCC TCT GAG AGC ACC AAC ACC ACC ATC GAG GAT GAA
mly CAG TTA ATG GAA TCC TCA GAG AGC ACC AAC ACC ACC ATC GAG GAT GAA

Asp Thr Lys Val Arg Lys Glu Glu Tl De Lys Val Thr Glu Gin Leu rat GAC ACC AAA GTG CGC AAA CAG GAA ATT ATC AAA GTO ACA GAG CAG CTG

Ile Glu Ala lle Ser Asn Gly Asp Phe Glu Ser Tyr Thr Lys Met Cys ral ATC GA ACC ATA AGC AAT GGA GAC TTT GAA TCC TAC ACG AAG ATG TGC

Asp Pro Gly Met Thr Ala Phe Glu Pro Glu Ala Leu Glu Asn Leu Val rat GAC CCT GGA ATG ACA GCC TTT GAA CCG GAG GCC CTG GGG AAC CTG GTC mky GAC CCT GGC ATG ACA GCC TTC GAA CCT GAG GCC CTG GGG AAC CTG GTC

1184

Glu Gly Leu Asp Phe

rat GAG GGC CTG GAC TITCA

Q

GLUTAMIC ACID DECARBOXYLASE

1323 Pro His Lys Met Met Gly Val Leu Leu Gin Cys Ser Ala Ile Leu mky CCT CAC AAG ATG ATG GGC GTG CTG TTG CAG TGC TCT GCC ATT CTC

Val Lys Glu Lys Gly Ile Leu Gln Gy Cys Asn Gin Met Cys Ala mky GTC AAA GAA AAG GGT ATA CTC CAA GGA TGC AAC CAG ATG TGT GCA

Gly Tyr Leu Phe Gin Pro Asp Lys Gin Tyr Asp Val Ser Tyt Asp mky GGA TAC CTT TTC CAA CCA GAC AAG CAG TAT GAT GTC TCC TAC GAC

Thr Gly Asp Lys Ala Ile Gln Cys Glu Arg His Val Asp Ile Phe cat AC, GGG GAC LyG Ala Ile Glo Cys GIU Arg GAC Val Asp

Lys Phe Trp Leu Met Trp Lys Ala Lys Gly Thr Val Gly Phe Glu al AAG TTC TOO CTO ATO TOG AAA GCA AAG GGC ACA GTG GGA TTT GAA mly AAG TTC TGG CTG ATG TGG AAA GCA AAG GGC ACA GTG GGA TTT GAA

Asn Gln Ile Asn Lys Cys Leu Glu Leu Ala Glu Tyr Leu Tyr Ala

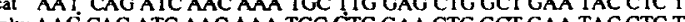

Lys De Lys Asn Arg Glu Glu Phe Glu Met Val Phe Asp Gly Glu cat Lys be Lys Asn Arg Glu Glu Phe Glu Met Val Phe Asp Gly Glu mky AAG ATT AAA AAC AGA GAA GAA TTT GAG ATG GTT TTC GAT GGT GAG

Pro Glu His Thr Asn Val Crs Phe Trp Tyr lle Pro Gin Ser Leu cat CCT GAG CAT ACA AsT GTC TGT TTC TGG TAT ATT CCA CAAAGC CTC mky CCT GAG CAT ACA AAT GTC TGT TTC TGG TAT ATT CCA CAA AGC CTC

Figure 1. Sequences of monkey CaM II kinase $\alpha$ and $\alpha-33$ and GAD cDNA clones. $A$, Schematic representation of predicted CaM II kinase protein structures. The solid white box designates regions that are highly conserved between all subunits. Hatching on the main figure indicates the $\alpha-33$ insert. Black bars represent oligonucleotides used in PCR experiments. The $\beta$ subunit inserts represent sequences unique to the $\beta$ transcripts; the hatched region on right insert is deleted in the $\beta^{\prime}$ transcript (Bulleit et al., 1988). $B$, Monkey Cam II kinase $\alpha / \alpha-33$ sequence is aligned to homologous region of rat CaM II kinase $\alpha$ cDNA sequence (Lin et al., 1987). The $\alpha-33$ insert begins at nucleotide 984 of the rat sections as controls for the in situ hybridization. In all control sections, the visual cortex showed no labeling above background (see Fig. 2D,E). In addition, the 2 antisense riboprobes used in this study (GAD and CaM II kinase) served as controls for one another because they possess similar guanine/cytosine ratios.

\section{Results \\ Cloning}

Eight PCR-generated CaM II kinase $\alpha$ cDNA clones derived from monkey cortex were sequenced. Six of the clones (CaM II kinase $\alpha$ ) had a $95 \%$ sequence identity with rat CaM II kinase $\alpha$ cDNA in the comparable region (Lin et al., 1987). However, 2 of the clones (CaM II kinase $\alpha$-33) contained a 33-base-pair (bp) insert at the point where rat CaM II kinase $\alpha, \beta$, and $\beta^{\prime}$ subunit sequences diverge (Bulleit et al., 1988; Fig. 1A,B). Apart from the 33-bp insert, the 2 CaM II kinase $\alpha-33$ clones were identical to the $6 \mathrm{CaM}$ II kinase $\alpha$ clones. Four of the 8 clones contained 1 of 2 base substitutions. Both nucleotide changes are in the third nucleotide of a codon and do not alter the amino acid encoded. These substitutions probably represent errors known to be introduced following several rounds of amplification (approximately $0.1 \%$; Saiki et al., 1988).

Three 360-bp monkey GAD cDNA clones were generated using PCR and sequenced. In all 3 , the $5^{\prime}$ end contains the proposed pyridoxal phosphate-binding region that is conserved between pig dopa decarboxylase cDNA (Bossa et al., 1977) and cat GAD cDNA (Kobayashi et al., 1987). One of the 3 sequences contains a single nucleotide change, but this change would not alter the amino acid encoded. There was $97 \%$ sequence homology with cat GAD cDNA in this region (Fig. $1 C$ ).

\section{Transcript analysis by $S 1$ nuclease protection}

${ }^{32}$ P-labeled antisense CaM II kinase $\alpha$-33 (CaM II kinase cRNA) was used to analyze CaM II kinase mRNA, because it would identify mRNAs complementary both to itself and to CaM II kinase $\alpha$. In assays from both deprived and nondeprived visual cortex RNA, 3 protected bands of mRNA were observed. The largest protected fragment was approximately $350 \mathrm{bp}$, which is the predicted size for CaM II kinase $\alpha-33$. Two smaller fragments, approximately 200 and $116 \mathrm{bp}$, were the predicted sizes for a CaM II kinase $\alpha$ transcript that has been cleaved by S1 nuclease at the location of the 33-bp insert (Fig. 2A,C). Thus, both CaM II kinase $\alpha$ and CaM II kinase $\alpha-33$ are expressed in normal and deprived visual cortex.

When monocularly deprived and nondeprived RNA samples were compared, different densities of protected CaM II kinase mRNA levels were commonly observed. However, when densitometry readings from the CaM II kinase S1 autoradiograms were normalized to film densitometry readings of antisense cyclophilin probes protecting the same RNA samples, consistent

sequence; a gap is inserted in the rat $\alpha$ sequence to maintain alignment. The oligonucleotides used in the PCR procedure are underlined. Nucleotide differences are indicated by small dots, and amino acid differences are indicated below the monkey sequence. Four of 8 clones had 1 of 2 base substitutions $\left(T^{*}, T \S\right)$. The consensus phosphorylation sequence in $\alpha-33$ is boxed. $C$, Monkey GAD sequence is aligned to homologous regions of cat GAD cDNA sequence (Kobayashi et al., 1987). Oligonucleotides used for PCR are underlined. Nucleotide differences are indicated by small dots. $C^{*}$, base substitution found in 1 of 3 sequences. The proposed pyridoxal phosphate binding region is boxed. 


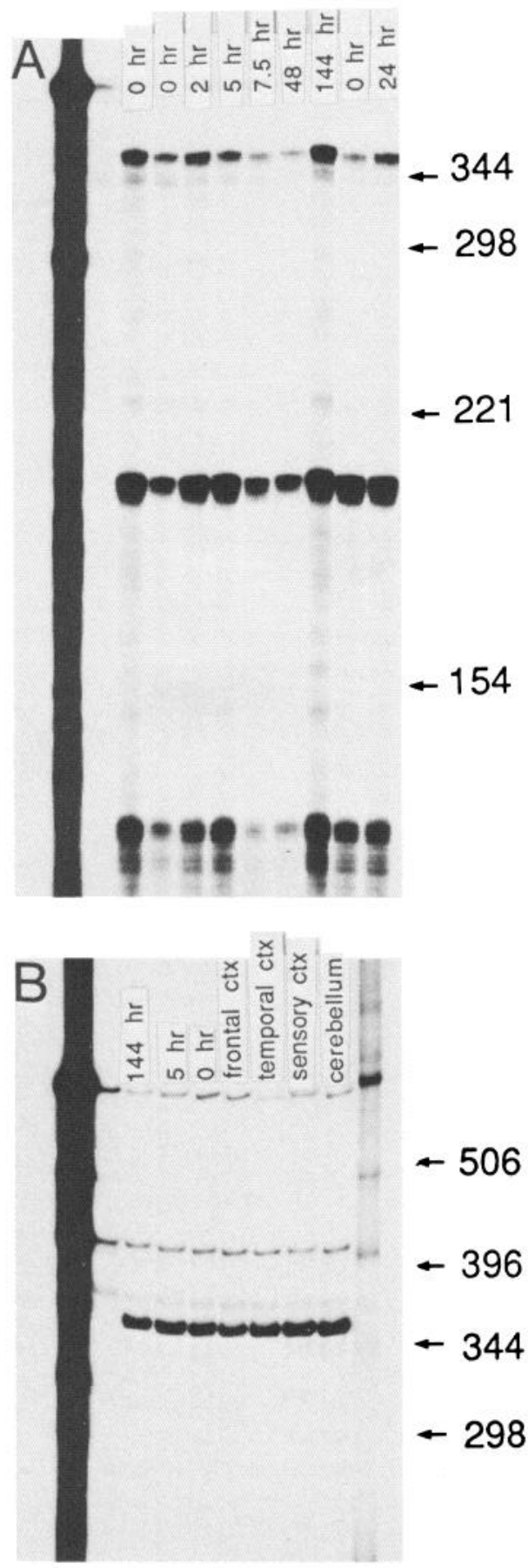

$\mathrm{C}$

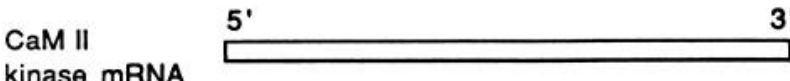

antisense CaM II kinase $\quad 517$ bases alpha-33

protected fragments $\square$ \# $116+201$ base pairs

CaM II

mRNA

antisense CaM II kinase

517 bases

alpha-33

protected fragment

350 base pairs
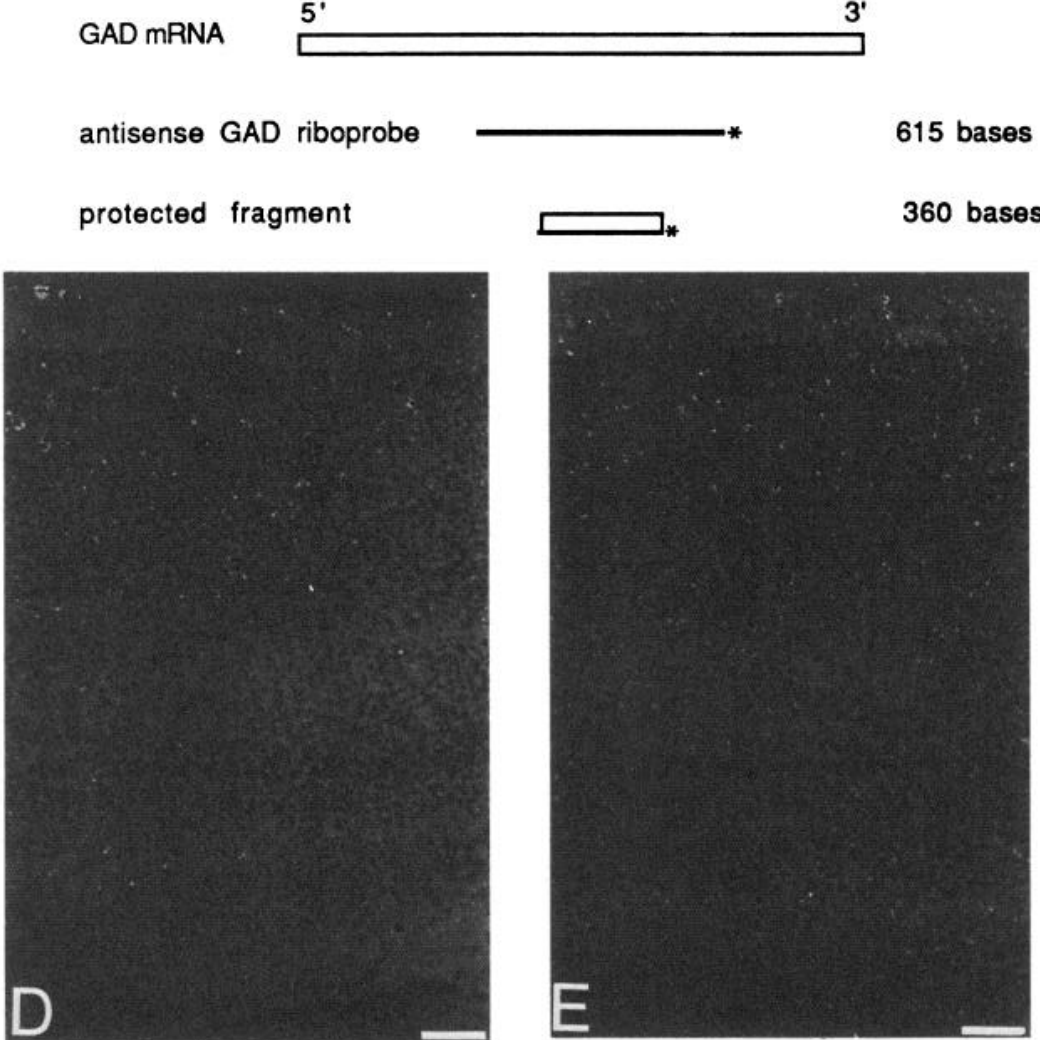

Figure 2. Predicted GAD and CaM II kinase transcripts in normal and monocularly deprived visual cortex. $A$, and $B$, S1 nuclease protection experiments. $A$ shows protection of CaM II kinase $\alpha-33$ probe shown in the upper portion of $C$ where hatching indicates the 33 bp insert. $B$ shows protection of GAD probe shown in lower portion of $C$. In $A$ and $B$, the far left lanes contain undigested probe; the second lanes contain digested probe protected with wheat germ tRNA alone. All other protected RNA is from the visual cortices of monkeys that had been monocularly deprived for the hours indicated (normal $=0$ hour) or from other brain regions as indicated. Size markers were ${ }^{32} \mathrm{P}$-labeled Hinfl-digested pBR322 fragments. $C$, Antisense probes used in $\mathrm{S} 1$ nuclease protection and the sizes of predicted RNA fragments. $D$ and $E$, Photomicrographs of autoradiographs from area 17 of a normal monkey showing background labeling obtained with hybridization of CaM II kinase $(D)$ and GAD $(E)$ sense probes. Scale bars, $100 \mu \mathrm{m}$.

changes in the amount of CaM II kinase $\alpha$-encoding mRNA could not be detected $(p=0.1)$. In situ hybridization, as indicated below, proved to be a more reliable indicator of a deprivation effect.

Antisense GAD was used to protect RNA from the visual cortex of both normal and monocularly deprived animals as well as from other cortical areas. In all cases, a single band of approximately $360 \mathrm{bp}$ was protected in film autoradiograms (Fig. 2B,C). The optical density of the protected bands, when read by a densitometer and normalized to cyclophilin readings, 


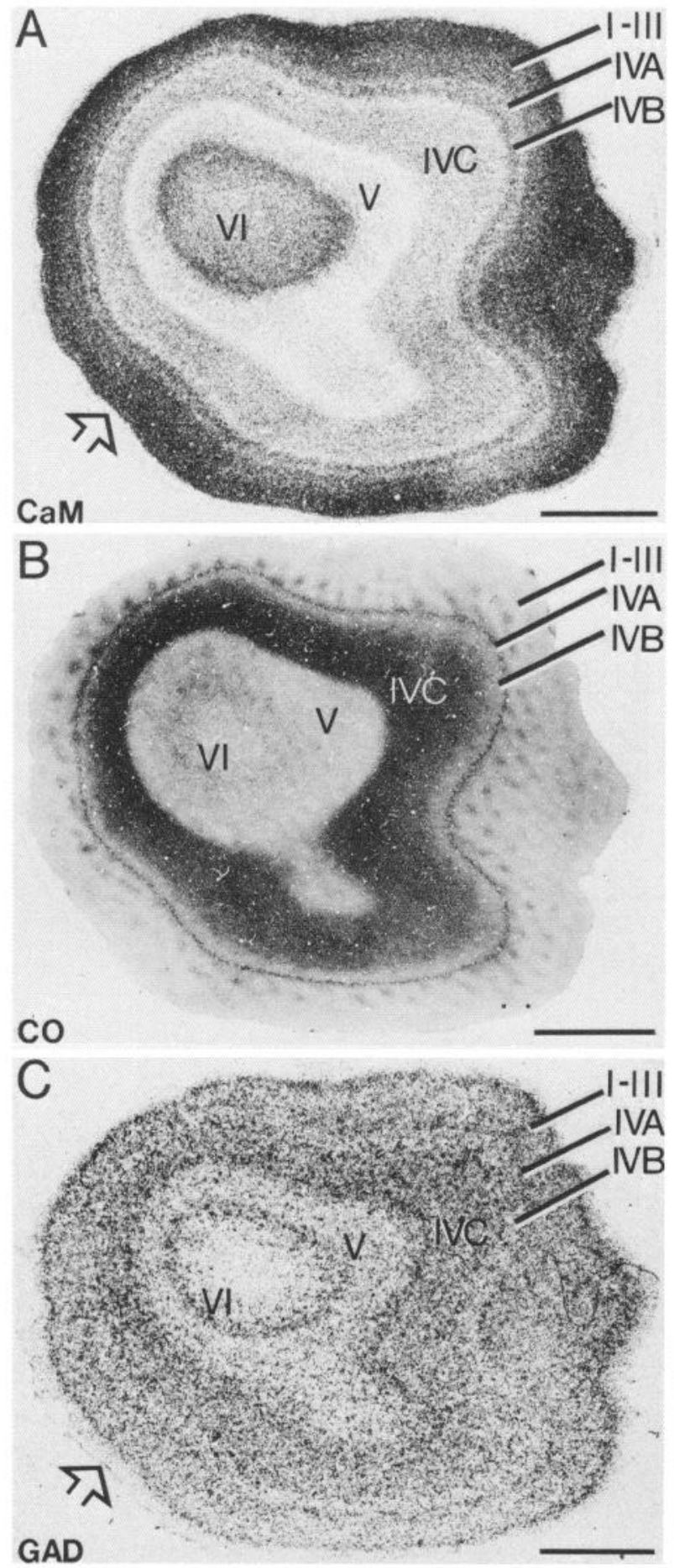

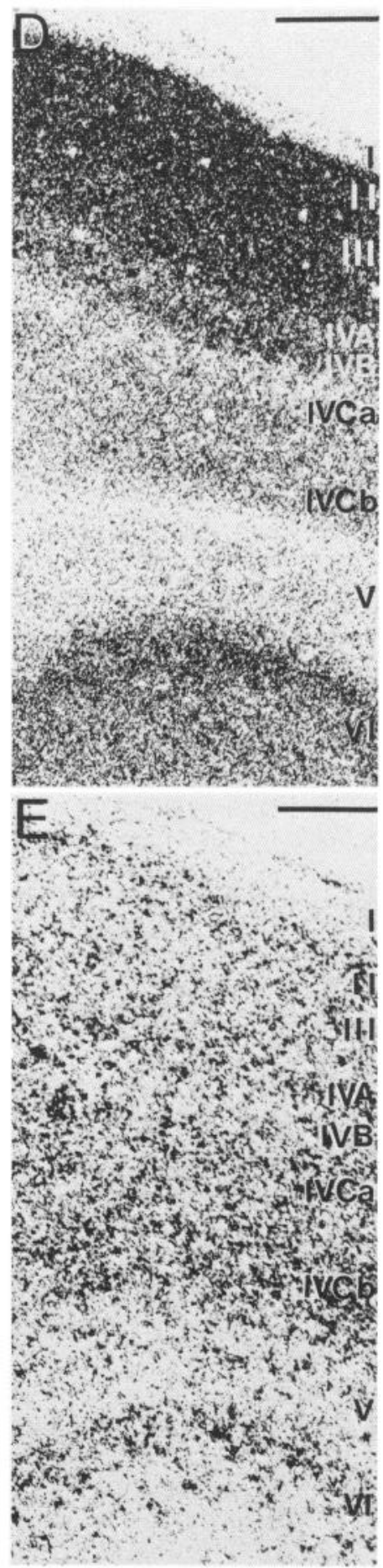

Figure 3. Localization of CaM II kinase $\alpha$ and GAD mRNA in normal visual cortex: bright-field photomicrographs of adjacent sections cut parallel to surface and hybridized with antisense CaM II kinase $(A, D)$, stained for $\mathrm{CO}(B)$, or hybridized with antisense $\operatorname{GAD}(C, E)$. In sections $A-C$, note the uniformity of hybridization/staining within layer IVC. Scale bars, $2 \mu \mathrm{m}$. D and $E$ are photomicrographs taken at higher magnification from $A$ and $C$ at the region indicated by the arrows. In $E$, one can see hints of sublamination in layers $I V C$ and $V I$ that become more readily apparent when larger portions of layer IV are cut tangentially (see Figs. 10, 11). Scale bars, $670 \mu \mathrm{m}$ showed no detectable differences in the amounts of GAD mRNA in normal and monocularly deprived visual cortex RNA samples $(p=0.1)$.

\section{Transcript localization in visual cortex by in situ hybridization CaM II kinase}

Normal. In the normal primary visual cortex (area 17), hybridization of ${ }^{35} \mathrm{~S}$-labeled CaM II kinase cRNA was very dense in layers II-VI, and within a single layer, the density of autoradiographic grains, indicating hybridization of the probe, was relatively homogeneous (Figs. 3, 4). Even with very short exposure times, the level of hybridization was exceedingly high, making it difficult to localize the overlying silver grains to individual cell somata. The pattern of hybridization was nevertheless very specific in that differences in density enabled cortical laminae to be discerned and laminar borders to be delineated. However, an unusually large amount of the hybridization signal, well above background, lay over the neuropil. Comparison with the underlying Nissl-stained pattern and with adjacent $\mathrm{CO}$ stained sections (Figs. 3,4 ) showed that layers II and IVB con- 

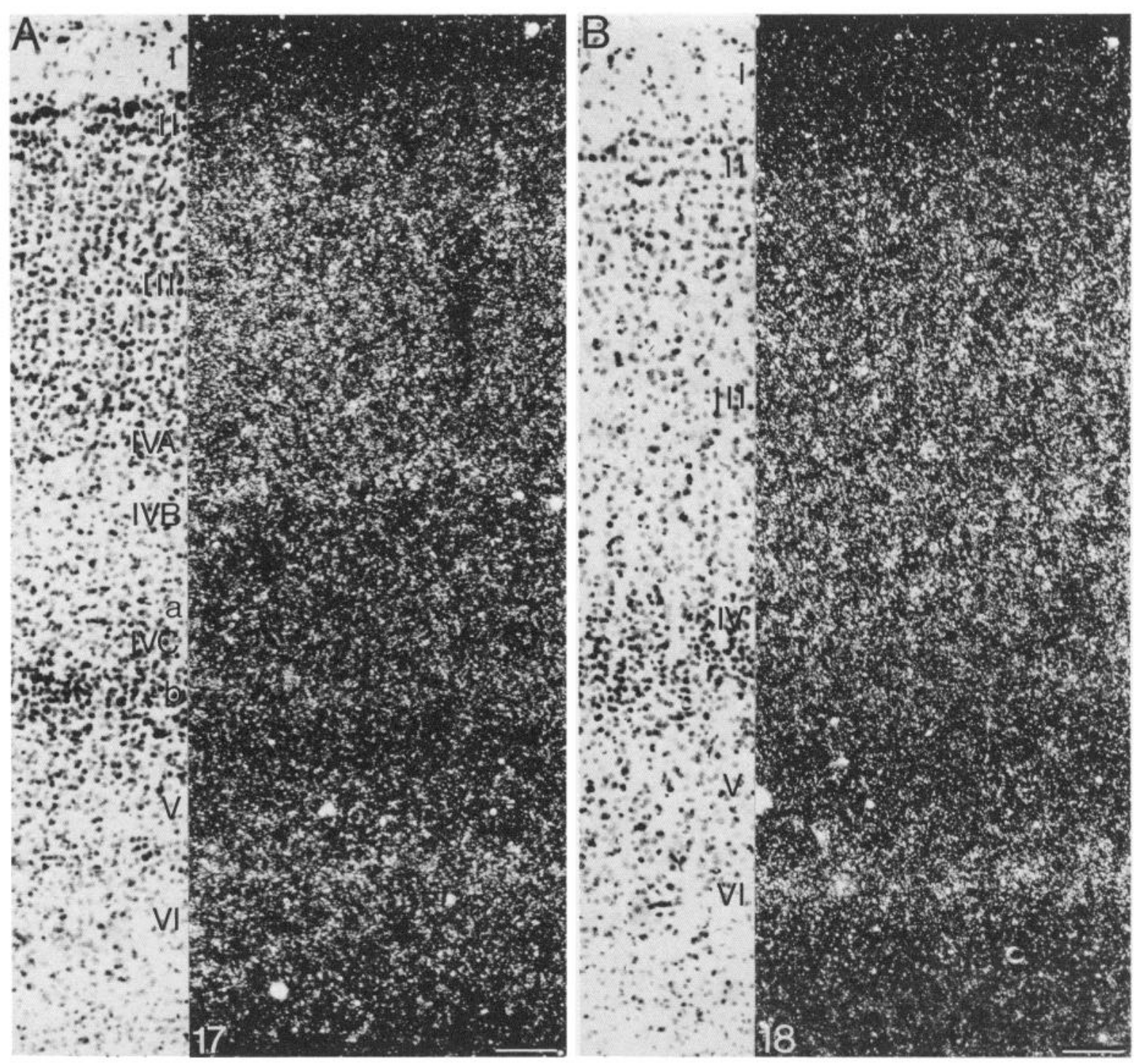

Figure 4. Dark-field photomicrographs of each pair show comparison of CaM II kinase in situ hybridization in autoradiographs from areas 17 and 18 of normal monkey. Paired bright-field photomicrographs of the underlying Nissl-stained sections show lamination patterns. $A$, In area 17 , hybridization levels are particularly high in layers $I I, I I I, I V B$, and $V I$, and levels within a single layer are relatively uniform. $B$, In area 18 , hybridization levels in layers $I V$ and $V I$ are enhanced relative to area 17. (See Results for further description.) Scale bars, $100 \mu \mathrm{m}$.

tained the greatest amount of CaM II kinase mRNA signal. Layers III, IVC $\beta$, and VI contained somewhat lesser amounts, though a narrow band in the upper portion of layer VI was more densely labeled. Levels were low in layers IVC $\alpha$ and V. Layers IVA and I contained the lowest levels, and a narrow strip at the border between layers IVC and V was almost devoid of hybridization (Fig. $3 A, B$ ). Within a layer, the hybridization pattern was homogeneous. No periodicities could be detected in the labeling pattern in layers II-VI in radial or tangential sections.

On moving from area 17 into area 18 , hybridization of $\mathrm{CaM}$ II kinase cRNA increased in layer III such that it was indistinguishable from layer II. The sublaminae of layer IV seen in area 17 collapsed into the single layer IV of area 18 at the 17-18 border. Layer IV in area 18 was homogeneously labeled at a level approximately equal to that of layer IVC $\alpha$ in area 17. Layer VI was more intensely labeled than in area 17, and its border with layer V was more distinct (Fig. 4). The level of neuropil hybridization was, as in area 17 , particularly high.
Adjacent sections hybridized with CaM II kinase sense-strand riboprobes revealed no labeling above background levels (Fig. 2D).

Deprived. Following monocular deprivation by TTX injection, retinal destruction, or eye removal, the pattern of CaM II kinase mRNA localization was dramatically altered at all survival times and in animals of all ages studied. CaM II kinase cRNA hybridization in area 17 was greatly enhanced in regular columns that extended from layers II through VI, and which alternated with similar columns showing lower levels of hybridization signal (Figs. 5-7). The changes in density of label were most evident in sections cut parallel to the pial surface where the alternating dense and less dense columns appeared as long stripes that were especially visible in layer IV. In layer IVC, the alternating stripes appeared of approximately equal width, measuring approximately $400 \mu \mathrm{m}$, and affected both layers IVC $\alpha$ and IVC $\beta$. In sections cut perpendicular to the surface, they were more difficult to identify because of the generally high- 


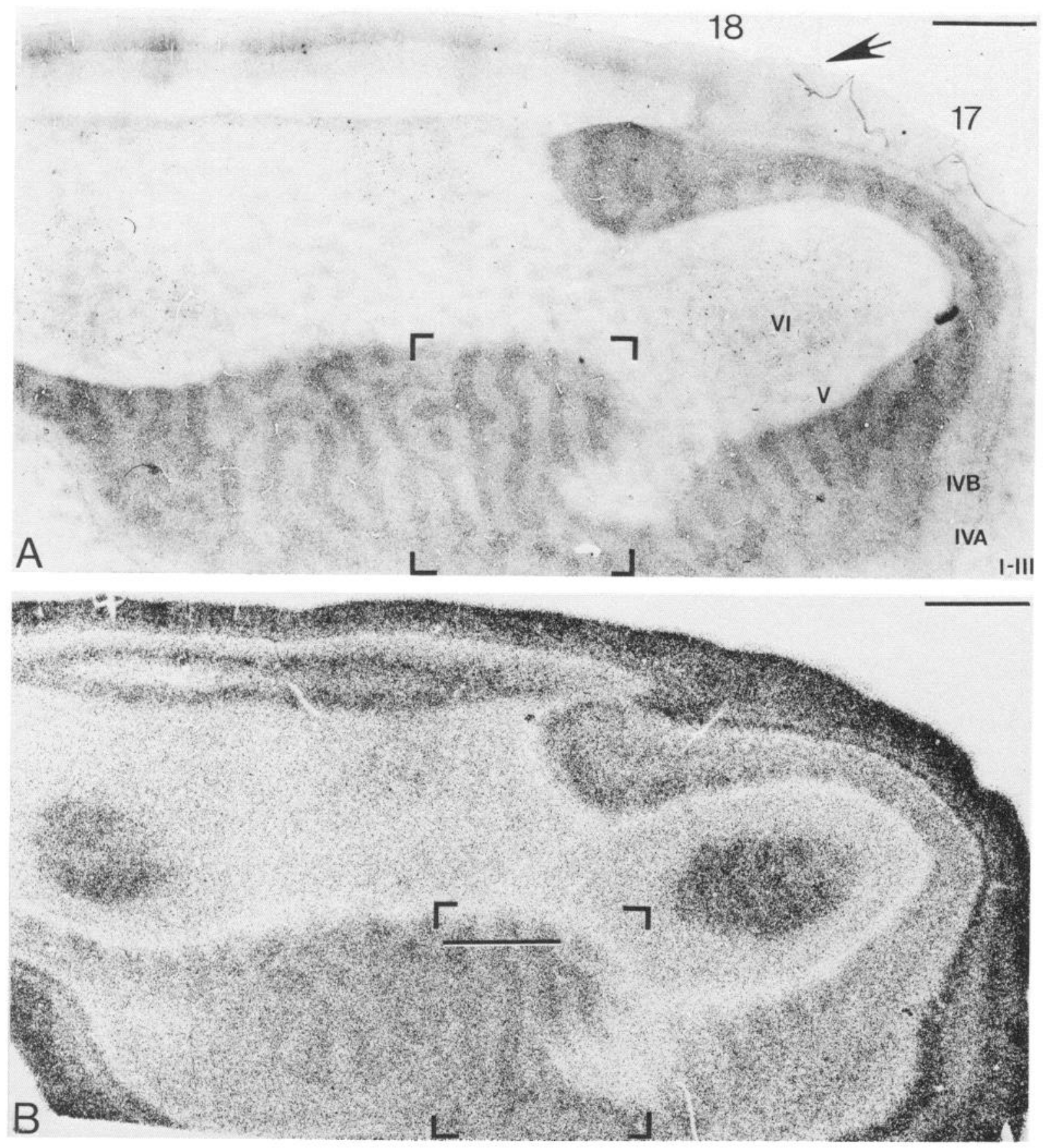

Figure 5. Photomicrographs of CO staining $(A)$ and CaM II kinase cRNA hybridization $(B)$ in tangential sections through area 17 of monkey that had been monocularly deprived by TTX injection $48 \mathrm{hr}$ prior to death. $A$, The CO staining in layer IVC is divided into alternating light (deprived) and dark (normal) stripes, and stained patches can be seen in layers $I I, I I I, V$, and $V I$. B, CaM II kinase cRNA hybridization is also divided into alternating light and dark stripes in layer IVC. Stripes can also be seen in layer VI. The arrow in $A$ denotes the area $17 /$ area 18 border, and boxed regions in $A$ and $B$ with correlative markers can be seen at higher magnification in Figure 7 . The line in $B$ shows the direction traversed in making the quantitative assessment in Figure 6. Scale bars, $2 \mathrm{~mm}$.

grain density overall. A correlation of the columns and stripes in layer IVC with ocular dominance columns was made from the adjacent CO-stained sections in which long stripes of light and dark CO staining appear in layer IVC and in which profiles of the same sectioned blood vessels could be superimposed on those found in the adjacent autoradiograph (Figs. $5 A, B ; 7 A, B$ ). Because the vessels enter the cortex along radial trajectories, this provides an accurate guide to localization from section to section. It was clear from this comparison that the stripes of enhanced in situ hybridization corresponded to the lightly stained $\mathrm{CO}$ stripes and, thus, to deprived ocular dominance columns, while the stripes showing weaker hybridization corresponded to the darker $\mathrm{CO}$ stripes and, thus, to nondeprived columns (Wong-Riley, 1979; Horton and Hubel, 1981). The enhanced hybridization of CaM II kinase cRNA in the deprived-eye columns was apparent $48 \mathrm{hr}$ after monocular deprivation, had not 


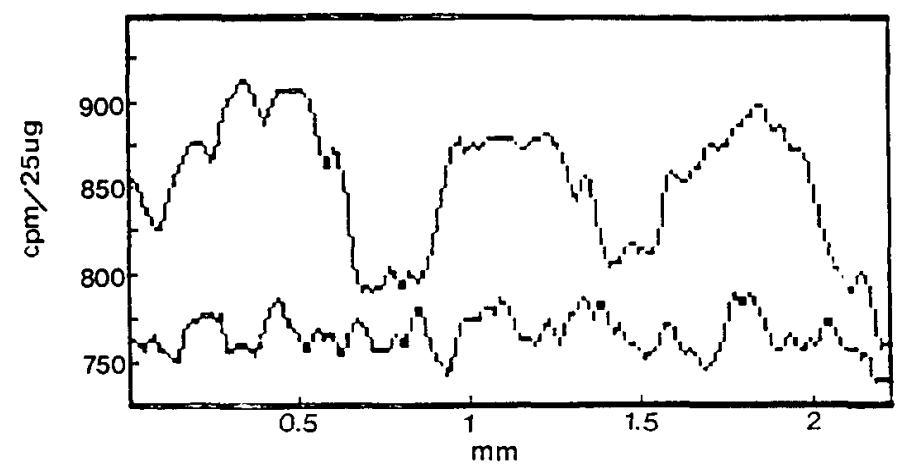

Figure 6. Line graph from image-density analysis. Autoradiographic grain density was measured from digitized images within a $2 \times 1 \mathrm{~mm}$ square approximately half the size of the boxed area in Figure 5 and plotted against distance in the horizontal dimension of layer IVC. The upper line represents data taken from an area within the boxed region in Figure 5 (see direction of traverse in Fig. $5 B$ ). The lower line represents data taken from a comparable region of layer IVC of an autoradiograph of normal visual cortex that was processed for CaM II kinase in situ hybridization at the same time as the other. In the upper, deprived visual cortex line, peaks represent deprived-eye columns, and valleys represent the normal eye columns (see Fig. 7). No significant fluctuations can be seen in the lower line derived from normal visual cortex.

changed by $5 \mathrm{~d}$, and was still evident as late as $15 \mathrm{~d}$ after monocular deprivation. However, in the one animal examined $15 \mathrm{~d}$ after initial deprivation, the contrast between deprived and nondeprived columns, though maximal in the CO-stained sections, was less distinct than at the earlier time points in the autoradiographs.

The surface-parallel sections showed that striping in the pattern of hybridization similar to that in layer IVC extended up into layers II-IVB and down into layers V and VI (Fig. 8). In layers II and III, continuous stripes of higher autoradiographic grain density, approximately $500 \mu \mathrm{m}$ wide, alternated with less dense stripes approximately $300 \mu \mathrm{m}$ in width. Superimposition on the immediately adjacent $\mathrm{CO}$-stained section, using the sectioned profiles of the radial blood vessels as guides, revealed that the denser stripes of hybridization in layers II and III lay over rows of the CO-stained periodicities ("blobs") that lie at the centers of ocular dominance columns in these layers (Horton and Hubel, 1981; Horton, 1984). Because the patches of $\mathrm{CO}$ staining in the rows of deprived-eye periodicities become shrunken in longer-deprived animals (Horton, 1984; Fig. 8C), a direct correlation of the stripes of labeling and ocular dominance columns could be made. This revealed that the wider, denser stripes of hybridization lay over rows of shrunken $\mathrm{CO}$ stained periodicities representing the deprived eye and extended over the weakly $\mathrm{CO}$-stained (interrow) regions on each side. The narrower, less dense stripes of hybridization lay over the intervening rows of nonshrunken periodicities representing the nondeprived eye (Fig. 8C,D).

Layer IVA was too lightly labeled overall to detect rows or stripes in the hybridization pattern, but stripes could be clearly identified in layers IVB, V, and VI, as well as in the intervening layer IVC. In layers IVB, V, and VI, slightly wider stripes of enhanced hybridization alternated with somewhat narrower stripes of less dense hybridization. Those in layer VI were denser than in the other 2 layers (Fig. $8 E, F$ ). In all cases, the stripes were aligned with the rows of $\mathrm{CO}$-stained periodicities detect- able with greater or lesser clarity in these layers (Horton, 1984). Superimposition of sections, using blood vessel profiles as guides, showed that the denser stripes of hybridized label lay in relation to rows of periodicities that lay above (layer IVB) or below (layers V and VI) the dense stripes of hybridization signal representing the deprived-eye dominance columns in layer IVC.

Autoradiograms of surface-parallel sections through layer IVC were subjected to quantitative image density analysis. In those from monocularly deprived animals, an area measuring $2 \times 1$ $\mathrm{mm}$, with its long axis running perpendicular to a series of ocular dominance stripes, was digitized. The labeling density was compared with that measured in rectangles of the same size from autoradiograms of sections through normal layer IVC and hybridized at the same time (Fig. 6). The digitized images of the autoradiograms from the deprived cortex were also superimposed on similarly digitized images from the same region of the adjacent $\mathrm{CO}$-stained sections to define accurately the positions of the ocular dominance stripes. Average labeling density in deprived-eye stripes was approximately $16 \%$ (range, $8-25 \%$ ) greater than in nondeprived stripes. In the latter, labeling density was approximately equal to that seen in normal layer IVC.

No inhomogeneities in the hybridization pattern could be detected in area 18 of normal or monocularly deprived monkeys (Fig. 5).

\section{$G A D$}

Normal. The distribution of label indicating hybridization of GAD cRNA spanned all layers of normal area 17 (Figs. 3C, 9). Silver grains associated with the hybridized antisense GAD riboprobes were distinctly localized over cell somata, by contrast with the more diffuse CaM II kinase hybridization pattern. Large and small clusters of silver grains could always be associated with underlying Nissl-stained cell nuclei (Fig. 9C,D). The large clusters measured approximately $21 \mu \mathrm{m}$ in diameter, and the small clusters, approximately $10 \mu \mathrm{m}$. Because of the RNase treatment of the sections following hybridization, only the cell nucleus was readily visible in Nissl stains. Therefore, somal size could not be accurately measured. It was presumed that largeand small-grain clusters probably corresponded to large and small cells, respectively.

Large and small clusters with varying numbers of grains were present in all layers. Differences in their proportions and density revealed a distinct laminar organization that was far more complex than the lamination visible in adjacent Nissl- or CO-stained sections. In the autoradiographs, the laminae of differential grain density were best distinguished from one another in sections cut somewhat obliquely, because each lamina then acquired a greater thickness than in sections cut perpendicular to the pia mater (Figs. $3 B, C ; 10 ; 11$ ). Occasional small clusters of a few grains were observed throughout layer I. Both large and small clusters with differing grain densities were found throughout layers II and III. Layer IVA appeared as a thin, densely labeled band separating layers III and IVB. Layer IVB had fewer small silvergrain clusters than layers II and III and was dominated by large clusters that were aggregated, forming a thin strip in the middle of the layer. Overall, layer IVC was characterized by small clusters of label containing few grains and probably indicative of lightly labeled small cells. Differences in the intensity of labeling revealed layers IVC $\alpha$ and IVC $\beta$ and further divided them into sublaminae (Fig. 11). Layer IVC $\alpha$ possessed 2 sublaminae: The upper portion was wider and had a greater amount of label than the thinner, lower portion. Layer IVC $\beta$ possessed 3 subalminae: 

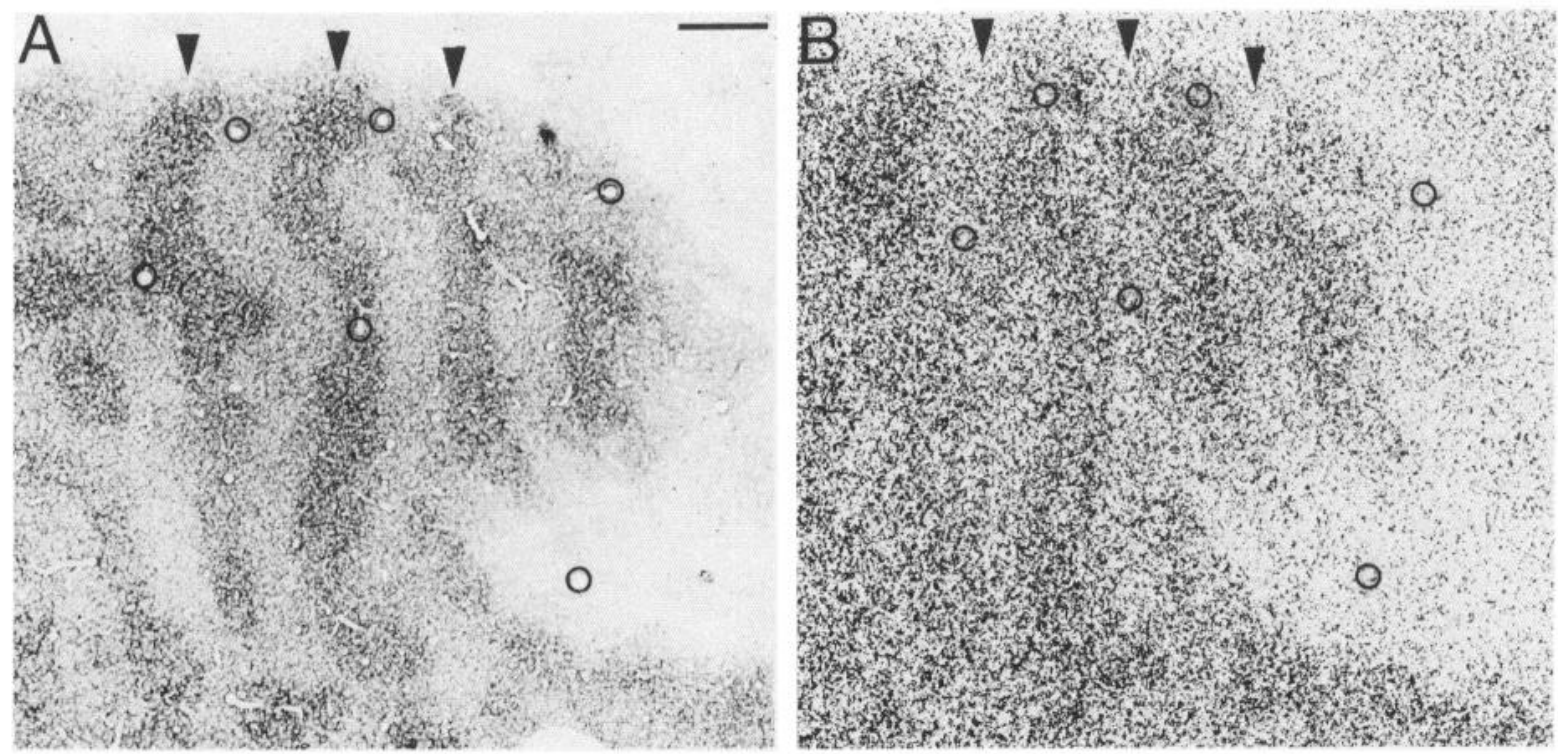

Figure 7. Higher-magnification bright-field photomicrographs taken from boxed regions in Figure 5 and including the region quantified in Figure 6. CO staining $(A)$ reveals normal- (arrowheads) and deprived-eye columns. The adjacent section $(B)$ hybridized with antisense CaM II kinase is also divided into dark and light bands. Comparison of positions of sectioned profiles of the same radially oriented blood vessels in the 2 sections (circles) shows that the dark kinase bands align with the light (deprived) $\mathrm{CO}$ bands. Scale bar, $500 \mu \mathrm{m}$.

2 relatively densely labeled bands separated by a less dense band. The labeling intensity of the denser bands was approximately equal to the labeling intensity of the upper portion of layer IVC $\alpha$. Layer V could be distinguished from layer IVC by a decrease in overall grain density, but with the reappearance of large clusters of grains. Layer VI, like layer IVC $\beta$, was subdivided into 3 laminae. The superficial and deep bands were more heavily labeled than a central, paler band. The entire layer was clearly dominated by large, densely packed clusters and possessed few small clusters.

In area 18, GAD hybridization levels in layers I, II, and III were approximately equal to levels in area 17 (Fig. 9), and the relative proportions of large- and small-grain clusters were also similar. Hybridization in layer IV was slightly denser than in the overlying layers, but revealed no sublaminae of the kind seen in area 17. Layers V and VI had fewer, but larger, silvergrain clusters than layer IV and about the same number as in area 17.
In sections of areas 17 or 18 cut parallel to the pial surface, GAD in situ hybridization was uniform, within single layers or sublayers in the horizontal dimension (Fig. $3 C, E$ ). When sections adjacent to those hybridized with GAD antisense riboprobes were hybridized with sense-strand probes, no labeling above background levels could be detected (Fig. 2E).

Deprived. Monocular deprivation by any of the 3 methods used at all times and in animals at all the ages studied resulted in no detectable alteration in the pattern of GAD cRNA hybridization in area 17 or area 18 (Figs. 10,11). The complex laminar pattern of GAD in situ hybridization in layer IVC revealed no irregularities that could be associated with the deprived- or nondeprived-eye dominance columns, demonstrable in the adjacent CO-stained sections.

Digitized images of the autoradiographs, when aligned with images of adjacent CO-stained sections, revealed no statistical difference between hybridization in deprived and nondeprived ocular dominance columns $(p=0.1)$. Because the $\mathrm{CO}$ staining

Figure 8. Paired CaM II kinase in situ hybridization $(B, D, E)$ and adjacent CO-stained sections $(A, C, F)$ cut tangentially through monocularly deprived visual cortex. $A$ and $B$, Adjacent sections are through layers II and III from the visual cortex of a monkey that had been monocularly deprived by TTX injection $48 \mathrm{hr}$ before death. CO staining in $A$ reveals rows of patches, the deprived members of which have not become shrunken at this short survival. CaM II kinase cRNA hybridization is broken up into a pattern of alternating light and dark stripes running horizontally across the figure. Positions of the same radially oriented blood vessels in the 2 sections are circled. $C-F$, Sections are from a monkey from which 1 eye had been enucleated $5 \mathrm{~d}$ before death. In layers II-III at this longer survival time $(C), \mathrm{CO}$ staining now reveals alternating rows of elongated (normal) and shrunken (deprived, arrows) patches. The adjacent section hybridized with CaM II kinase shows alternating light and dark bands oriented parallel to the rows of CO-stained patches. Positions of the same blood vessels are denoted by circles. Careful superimposition of $C$ and $D$ shows that the dark stripes overlie the rows of shrunken CO patches. (The reader may wish to overlay a tracing of one on the other.) $E$ and $F$, In layers $V$ and $V I, C a M$ II kinase hybridization pattern $(E)$ also delineates light and dark bands. An adjacent $C O$-stained section $(F)$ photographed from the region equivalent to that between the arrows shown in $E$ shows deprivation effect in layer IVC and rows of CO-stained patches in layers $V$ and VI. WM, white matter. Scale bars, $2 \mathrm{~mm}$.

Figure 9. $A$ and B, Dark-field photomicrographs of each pair show comparison of GAD in situ hybridization in autoradiographs of areas 17 and 18 from normal visual cortex cut perpendicular to the pial surface. Bright-field photomicrographs of the underlying Nissl-stained sections reveal lamination patterns. Large- and small-grain clusters delineate GABA cells in all layers. The complex sublamination seen in area 17 with GAD in situ hybridization in sections cut tangentially cannot be readily identified in this plane of section. Scale bars, $100 \mu \mathrm{m}$. $C$ and $D$, High-power brightfield photomicrographs illustrate large $(C)$ and small $(D)$ silver-grain clusters over Nissl-stained cell nuclei. Scale bars, $15 \mu \mathrm{m}$. 

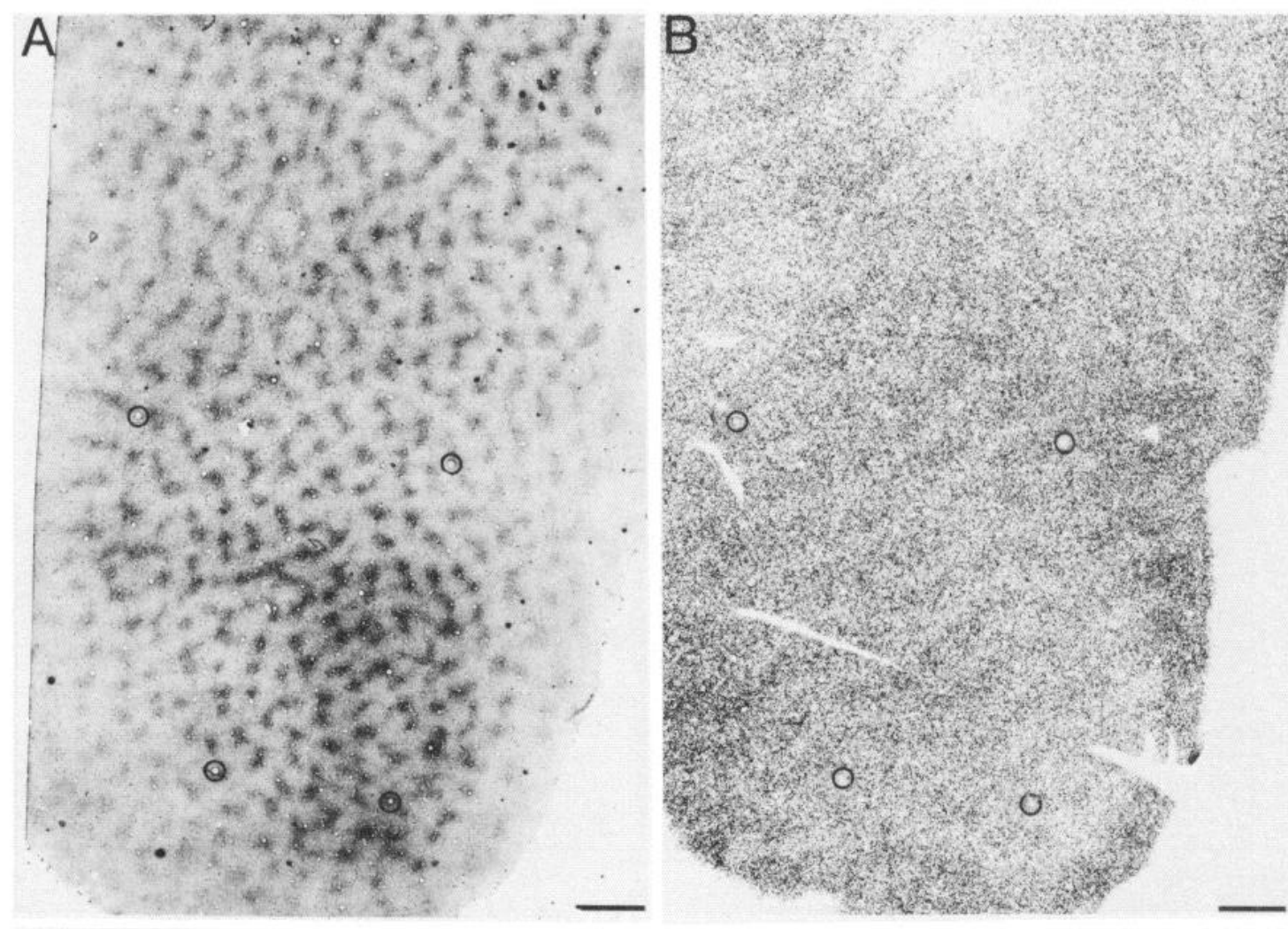

C
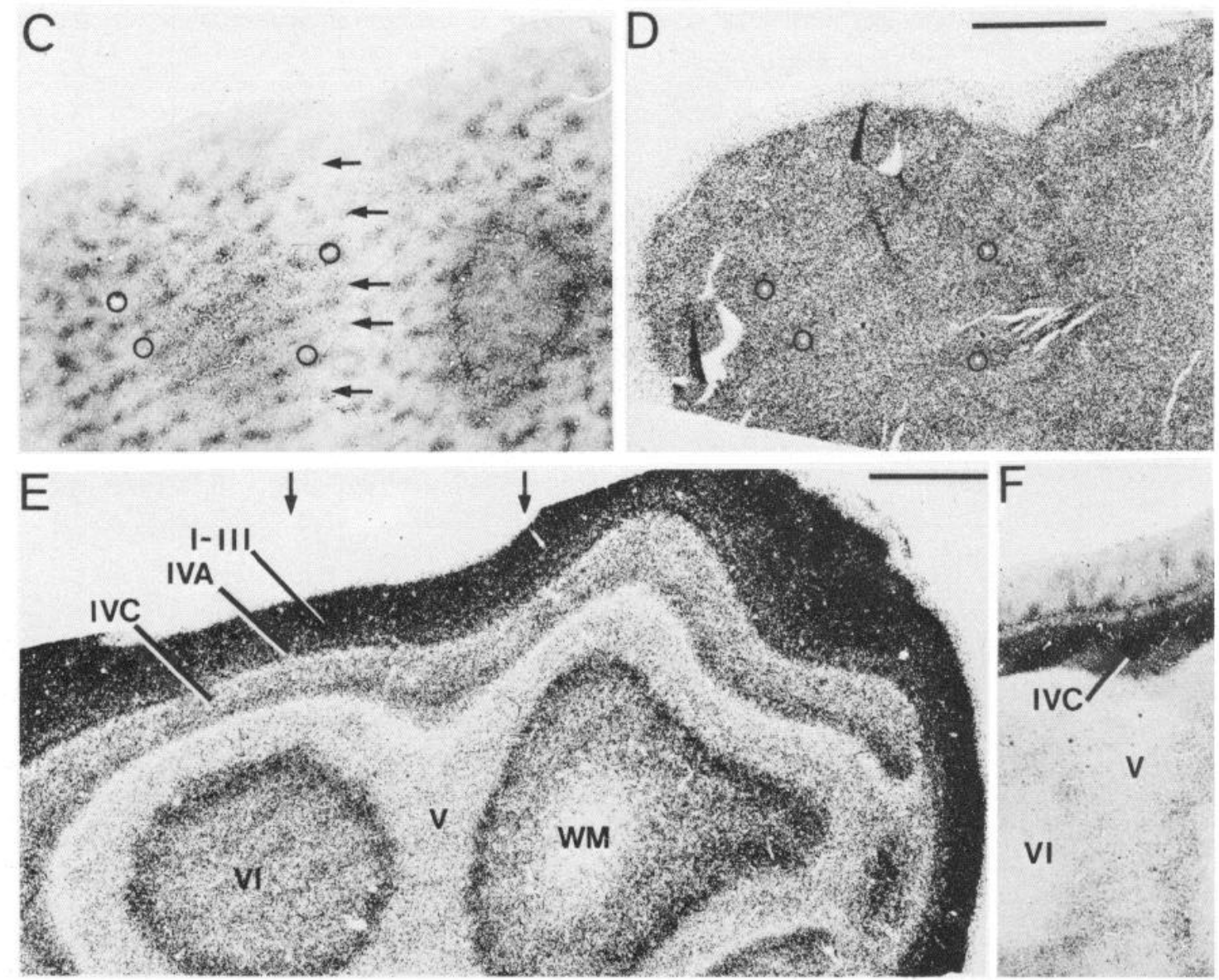


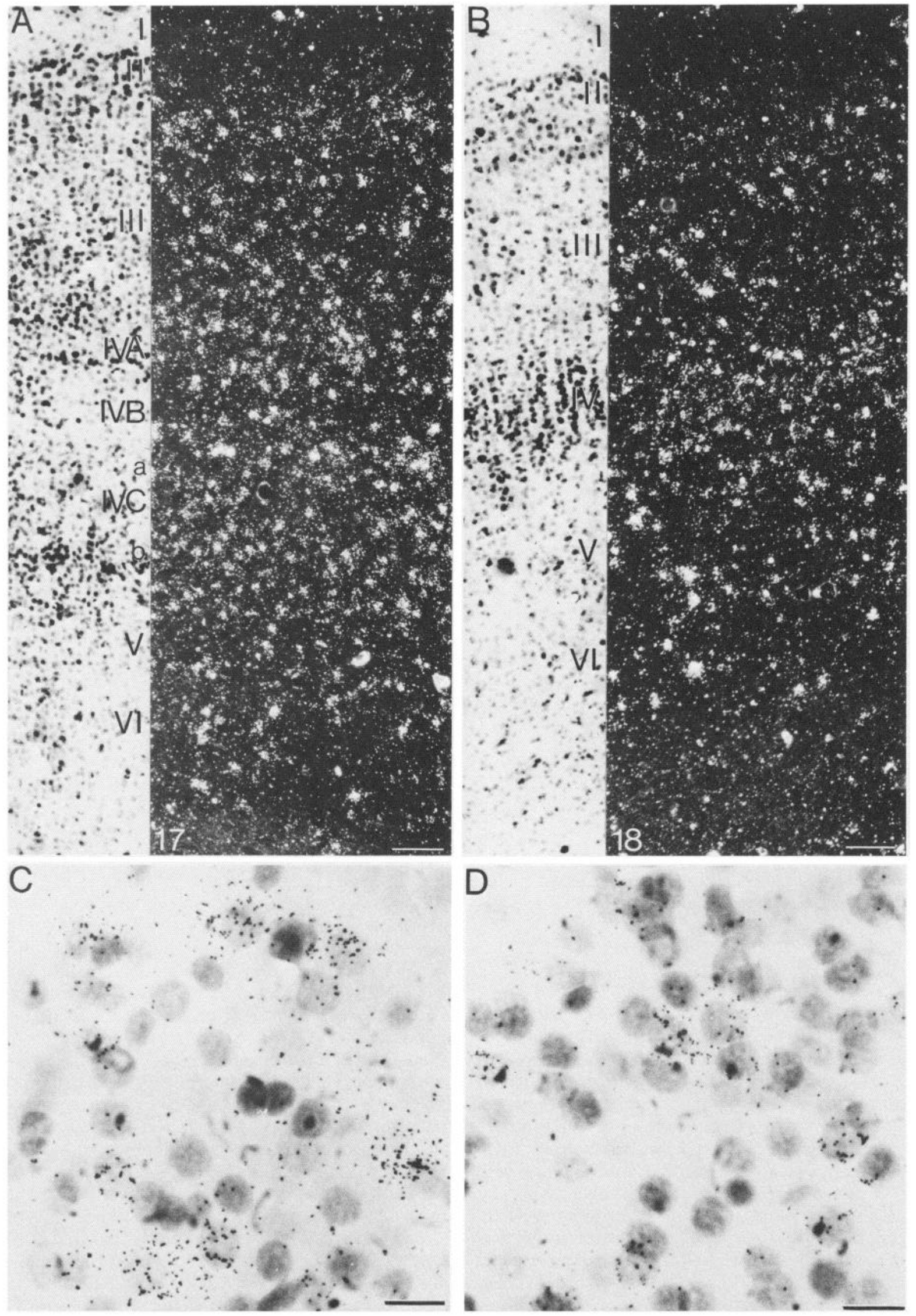


Figure 10. GAD in situ hybridization and $\mathrm{CO}$ staining in adjacent tangential sections from visual cortex of monkey that had been monocularly deprived for $5 \mathrm{~d}$ by destruction of ganglion cells by injected cobalt. $A$ is stained for $\mathrm{CO}$. Alternating light and dark bands in layer $I V C$ indicate deprived and nondeprived ocular dominance columns, respectively. $B$ has been hybridized with an antisense GAD probe. Note the absence of any pattern corresponding to the alternating ocular dominance columns seen in $A$. Note the normal sublaminae within layers $I V C \alpha, I V C \beta$, and $V I$, which are clearly visible in this plane of section. Arrows flank the regions that are shown at higher magnification in Figure 11. Scale bars, $2 \mathrm{~mm}$.

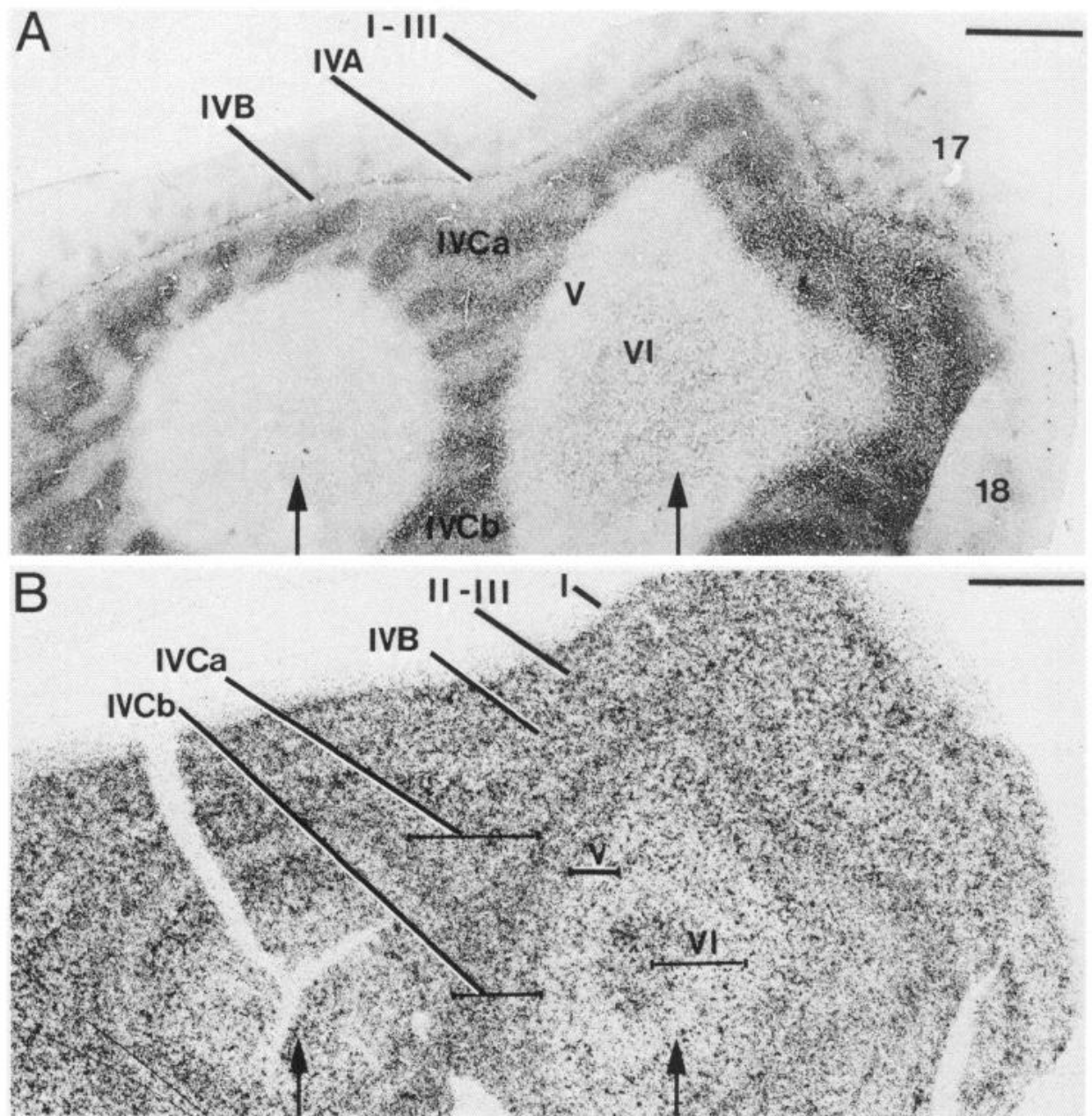

does not reveal the additional sublaminae of layers IVC $\alpha$ and IVC $\beta$, sampling could not be confined to the individual sublaminae seen in the autoradiographs. There were no detectable quantitative differences between layer IVC in normal and deprived area 17.

\section{Discussion}

Two principal conclusions can be drawn from this study. First, the increases in CaM II kinase immunoreactivity that have been demonstrated in nondeprived-eye columns of the adult monkey visual cortex following periods of monocular deprivation (Hendry and Kennedy, 1986) derive from corresponding increases in mRNA levels. Second, the large decreases in GAD immunoreactivity in deprived-eye columns of the adult monkey visual cortex following monocular deprivation (Hendry and Jones, $1986,1988)$ are not accompanied by corresponding changes in GAD mRNA levels; this implies that the deprivation effect on GAD levels is most likely mediated at a posttranscriptional level. The present study also revealed in the monkey cerebral cortex a second form of CaM II kinase $\alpha$ mRNA: CaM II kinase $\alpha-33$. The encoded protein would possess an additional consensus phosphorylation sequence. Finally, new sublaminar distributions of cortical GABA cells were revealed in layers IVC $\alpha$ and IVC $\beta$ of area 17.

\section{CaM II kinase $\alpha$ distribution}

CaM II kinase forms more than $1 \%$ of all forebrain protein in the rat (Erondu and Kennedy, 1985), and in the forebrain, the $\alpha$ subunit is particularly enriched (Miller and Kennedy, 1985). The similar abundance in monkeys is reflected in the intensity of the CaM II kinase hybridization pattern. The laminar distribution of neurons displaying hybridization of the CaM II kinase $\alpha$ cRNA in normal monkeys was similar to the distribution of CaM II kinase-immunoreactive cells indicated in previous studies (Hendry and Kennedy, 1986), though the high mRNA levels in the neuropil and, thus, presumably in dendrites was unexpected. Because CaM II kinase $\alpha$ immunoreactivity mostly delineates pyramidal cells (Hendry and Kennedy, 1986; D.L. Benson and E.G. Jones, unpublished observations), it is probable that hybridized probe over their long and densely packed apical and basal dendritic systems contributes to the more diffuse hybridization pattern (see also Burgin et al., 1990).

The large apical and basal dendrites of pyramidal cells contain significant amounts of free and attached ribosomes (Peters et al., 1976). CaM II kinase mRNA may therefore be translated at these sites as well as in the soma. It is unclear, however, whether the dendritic ribosomes and the dendritic CaM II kinase mRNA are specifically associated with the large numbers of dendritic spines and their associated asymmetrical synapes, 

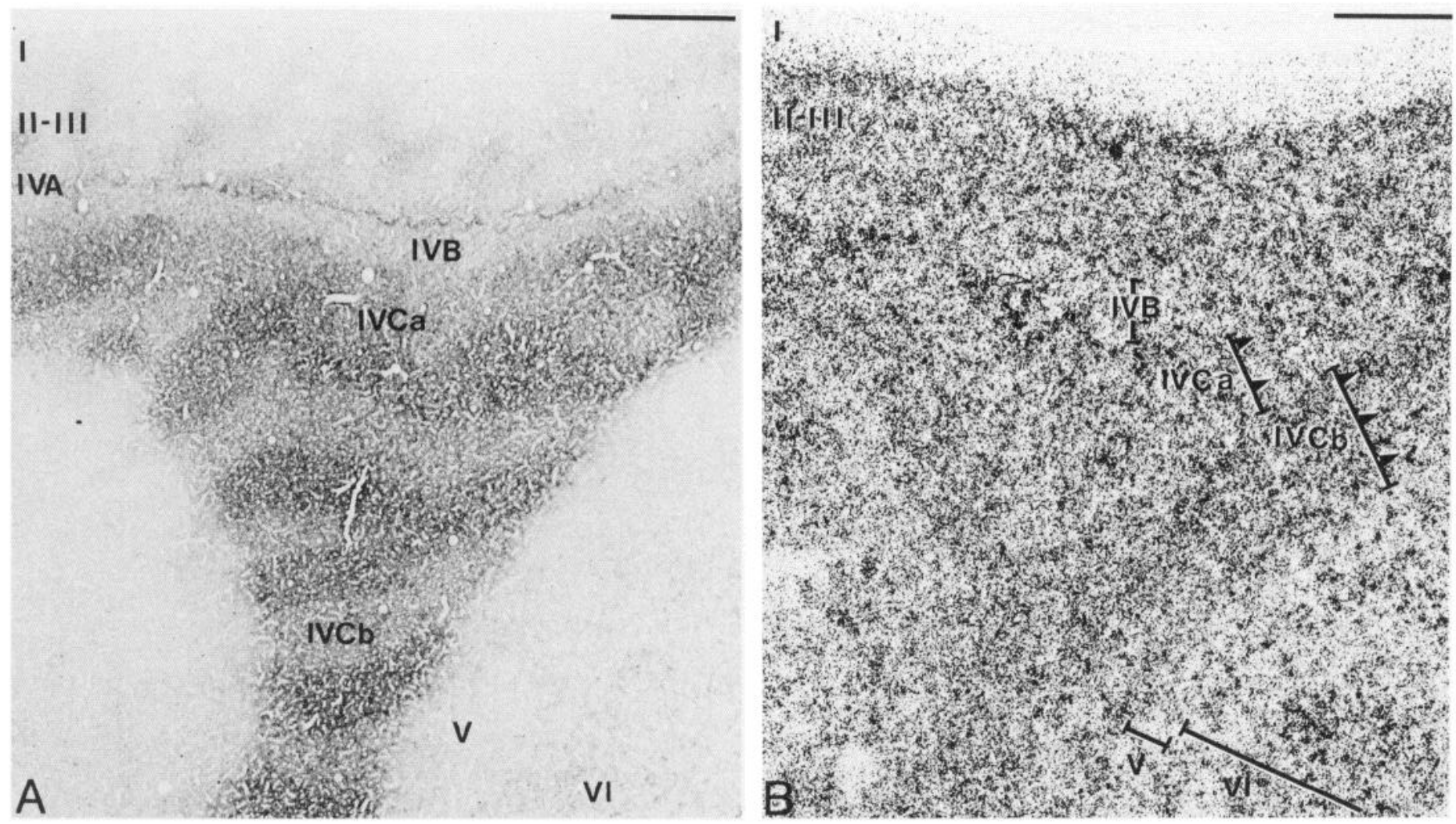

Figure 11. Higher-magnification bright-field photomicrographs of regions between arrows in Figure 10. The lack of a deprivation effect is clearly visible in $B$. The 2 sublaminae revealed by GAD in situ hybridization within layer IVC $\alpha$ and the 3 within layer IVC $\beta$ are denoted by arrowheads. Three sublaminae within layer VI are also readily apparent. Scale bars, $1 \mathrm{~mm}$.

though as a major component of the postsynaptic density (Kennedy et al., 1983; Kelly et al., 1984), CaM II kinase is probably located in large amounts at these synapses. A correlation of dendritic ribosomes and dendritic spines has been made for pyramidal cells of the rat hippocampal formation, and these may be involved in dendritic plasticity in the hippocampus (Steward, 1983).

\section{Activity-dependent regulation of CaM II kinase $\alpha$}

The present results provide further evidence for the importance of neuronal activity in regulating gene transcription in the CNS (see introductory remarks). CaM II kinase $\alpha$ immunoreactivity increases in deprived-eye dominance columns of layer IVC as early as $2 \mathrm{~d}$ following eye removal or intraocular TTX injection and after about 9 weeks of eyelid suture (Hendry and Kennedy, 1986; D.L. Benson and E.G. Jones, unpublished observations). The present results imply that this increase results either from up-regulation of CaM II kinase gene transcription or from increased stability of the mRNA in the deprived-eye columns. In view of the immunocytochemical results and the present quantitative assessments (Fig. 6), it seems unlikely that the striping seen in the hybridization pattern in the present results stems from a reduction of CaM II kinase mRNA in normal eye columns. The increase in immunoreactivity seen under deprived conditions would, from the present results, appear to reflect an increase in protein levels and not increased phosphorylation (Erondu and Kennedy, 1985) of the enzyme. The increase in CaM II kinase mRNA in the deprived-eye columns is evident within $48 \mathrm{hr}$ and can still be distinguished as late as $15 \mathrm{~d}$ fol- lowing monocular deprivation. It should be noted, however, that in the one animal examined at the later time point, the difference in hybridization between deprived- and nondeprivedeye dominance columns was less apparent than at the earlier time points examined. This could reflect interanimal variation. However, the prolonged increase in CaM II kinase $\alpha$ protein following monocular deprivation might be maintained by a different mechanism, such as increased protein stability. This will be a subject of future studies.

In monocularly deprived monkey visual cortex, CaM II kinase in situ hybridization reveals that the change in CaM II kinase expression is far greater than would be predicted on the basis of immunocytochemical localization of the enzyme. By using in situ hybridization, enhanced levels of CaM II kinase $\alpha$ mRNA can be demonstrated in deprived-eye dominance columns throughout layers II-VI. The effect of deprivation on CaM II kinase immunoreactivity was initially only detected in layer IVC $\beta$ (Hendry and Kennedy, 1986), but recent results suggest increases in immunoreactivity around $\mathrm{CO}$ periodicities related to deprived-eye columns in layer III as well (S. H. C. Hendry and E. G. Jones; unpublished observations). The ease with which an effect can be identified in all layers by in situ hybridization is most likely due to differences in the sensitivity of the techniques. However, decreased phosphorylation of the CaM II kinase $\alpha$ protein in layers other than layer IVC $\beta$ could prevent the immunocytochemical detection of a deprivation-based increase because the degree of phosphorylation affects immunoreactivity with the monoclonal antibody employed (Erondu and Kennedy, 1985).

The pattern of CaM II kinase probe hybridization and the 
pattern of CO staining in layers II and III of monocularly deprived visual cortex are inversely correlated. In deprived-eye columns, after a period of time, the $\mathrm{CO}$ patches in these layers are shrunken, and in the normal-eye columns, the patches expand and partially fuse with one another (Horton and Hubel, 1981; Horton, 1984; Wong-Riley and Carroll, 1984). Within the deprived-eye patches and in parts of the interrow regions adjacent to them, hybridization of CaM II kinase cRNA is enhanced relative to levels in the alternating rows of nondeprivedeye patches. This and the quantitative data from layer IVC make it apparent that CaM II kinase mRNA levels increase in the regions of decreased $\mathrm{CO}$ activity. The rows of enhanced hybridization in layers $\mathrm{V}$ and VI, therefore, probably also indicate increased CaM II kinase mRNA levels.

The effects of changes in CaM II kinase levels are likely to be varied and potentially long lasting. CaM II kinase can phosphorylate a wide range of substrates, including synapsin I, MAP2, tyrosine hydroxylase, and tryptophan hydroxylase (Bennett et al., 1983; Yamauchi and Fujisawa, 1983; Schulman, 1984; Vulliet et al., 1984); it enhances transmitter release from the presynaptic terminal of the squid giant synapse, probably in association with synapsin I (Llinás et al., 1985), and it increases vesicle mobility (McGuinness et al., 1989). It is a major postsynaptic density protein (Kennedy et al., 1983; Kelly et al., 1984), and in the mammalian hippocampus, it has been suggested to be essential for the induction of long-term potentiation (Malenka et al., 1989; Malinow et al., 1989). Effects of monocular deprivation may therefore be manifested at all these levels. An increase in CaM II kinase transcription resulting from visual deprivation in the adult monkey is likely to be a part of an entire cascade of second-messenger-related intracellular events that are set in motion by reduced activity entering deprived-eye dominance columns. These events undoubtedly include the regulation of immediate early genes whose gene products will be involved in the later regulation of CaM II kinase gene transcription. In this connection, it is important to note that several known immediate early genes have been shown to be induced in response to increased neuronal activity as well as to mitogens and growth factors (Greenberg et al., 1985; Morgan and Curran, 1986; Kujubu et al., 1987; Milbrandt, 1987; White and Gall, 1987; Saffen et al., 1988; Cole et al., 1989). It will therefore be interesting to determine which immediate early genes are induced or suppressed in response to decreased neuronal activity in the monocularly deprived monkey visual cortex.

\section{Functional implications of CaM II kinase $\alpha-33$}

CaM II kinase is a holoenzyme composed of the subunits $\alpha, \beta$, $\beta^{\prime}$, and, in view of the present results in the monkey, probably $\alpha-33$. The $\alpha$ and $\beta$ forms of CaM II kinase are encoded by different genes, but are highly similar (Bulleit et al., 1988). The major difference between the mRNAs encoding the subunits is a deletion from $\alpha$ of 2 segments that are present in $\beta$ and $\beta^{\prime}$ following the calmodulin-binding domain (Fig. 1 $A$ ). The inserted segments in the $\beta$ subunit within this region have been suggested to be responsible for different intracellular localization and autophosphorylation properties of holoenzymes containing different proportions of $\alpha$ and $\beta$ subunits (Bulleit et al., 1988; Miller et al., 1988).

Within the region cloned in this study, CaM II kinase $\alpha-33$ is identical to CaM II kinase $\alpha$ except for a strategically placed, hydrophilic, 33-nucleotide insert. This insert contains a potential phosphorylation site, Arg-Lys-Ser-Ser-Ser, which falls with- in the constraints for identified phosphorylation sequences in several CaM II kinase substrates (Pearson et al., 1985). In addition, this potential phosphorylation site is preceded by 2 lysine residues, which have been shown to affect the kinetics of phosphorylation of CaM II kinase substrates by substantially decreasing the $K_{m}$ (Pearson et al., 1985). In the presence of calcium and calmodulin, the $\beta$ subunit incorporates approximately 3 mol phosphate per mol subunit, while the $\alpha$ subunit incorporates only 2 mol phosphate (Miller and Kennedy, 1986). This difference has been attributed to the additional phosphorylation sites found in the $\beta$ form that are not present in the $\alpha$ form. CaM II kinase $\alpha-33$ provides an additional phosphorylation site that could make its calcium-dependent activity more like the $\beta$ form in regard to the ability to incorporate phosphate residues.

\section{GAD distribution}

The laminar distribution of GAD riboprobe hybridization in the visual cortex is far more complex than the lamination seen in comparable GAD and GABA immunocytochemical preparations (Hendrickson et al., 1981; Hendry and Jones, 1986; Fitzpatrick et al., 1987; Hendry et al., 1987). GAD and GABA immunoreactivity is confined to nonpyramidal neurons of both large and small sizes, with most of the larger cells being confined to layers III, IVB, and V. This pattern is reflected in the distribution of large- and small-grain clusters in the present in situ hybridization experiments. Hybridization of the GAD cRNA revealed distinct sublaminae in layers IVC $\alpha, \operatorname{IVC} \beta$, and VI. Two subdivisions of layer IVC $\alpha$ have been indicated by Fitzpatrick et al. (1987) on the basis of GABA-immunoreactive cell size. The present data show different GAD mRNA levels in rcgions corresponding to these sublaminae of layer IVC $\alpha$. However, no subdivisions comparable to those detected by in situ hybridization in layer IVC $\beta$ or in layer VI appear to have been described by immunocytochemistry.

\section{$G A D$ expression following monocular deprivation}

Earlier studies from this laboratory showed that, after $4 \mathrm{~d}$ of monocular deprivation by eye removal or TTX injection and after 7-9 weeks of monocular eyelid suture, approximately $50 \%$ of the GABAergic neurons in the deprived-eye dominance columns of the visual cortex had their GABA and GAD levels reduced below an immunocytochemically detectable threshold (Hendry and Jones, 1986, 1988; Hendry et al., 1987). These effects are reversible upon recovery from TTX or reopening of the eyelids (Hendry and Jones, 1988; D.L. Benson and E.G. Jones, unpublished obscrvations), indicating that they are dependent upon the presence or absence of impulse activity in the optic nerve.

However, by contrast with the activity-dependent regulation of CaM II kinase $\alpha$ mRNA, levels of GAD gene transcription appear to be maintained following monocular deprivation. This maintenance of GAD gene expression is also seen in the adult cat visual cortex following monocular deprivation (Benson et al., 1989a). There are 4 potential explanations for failure to detect a transcriptional change in GAD in the present experiments. First, GAD enzyme levels could be regulated by activity at the posttranslational level. A likely point of posttranslational regulation would be a modification such as deamidation, methylation, or limited proteolysis that would render the enzyme less stable or undetectable by immunocytochemistry (for review, see Benyon, 1980).

Second, there are likely to bc additional stages between DNA 
transcription and posttranslational processing that could be specifically regulated. Some of these stages could include covalent modifications of mRNA, transcript splicing, and the initiation of mRNA translation. In the case of GAD, mRNA maturation is not likely to be the stage regulated, because changes in polyadenylation or 5'-capping would affect mRNA stability and would be detected in the in situ hybridization studies as an increase or decrease in hybridization levels. It is possible that GAD gene expression is regulated by an alternative splicing event. However, at this time, there is no evidence to indicate that alternative splicing is utilized by cells to regulate the levels of gene expression. A more likely possibility is that mature, functional GAD mRNA is prevented from being translated. There is evidence that certain proteins are regulated at this stage of gene expression. For example, iron metabolism in higher eukaryotes is partially controlled by the iron-sequestering protein ferritin. When iron supplies are limited, ferritin mRNA translation is physically blocked (Klausner and Harford, 1989).

A third possible explanation is that the GAD gene examined in the present study maintains normal transcription levels while a second GAD gene is differentially regulated in response to monocular deprivation. Two GAD genes have recently been discovered. One codes for a $65-\mathrm{kDa}$ protein, and the other, for a 67-kDa protein (Kaufman et al., 1989; A. Tobin, personal communication). Immunocytochemical evidence shows the proteins to be colocalized in GABA cells, but with different intracellular distributions (Houser et al., 1989). The GAD gene studied in the present paper corresponds to the 65-kDa protein, and one of the polyclonal antisera used in our earlier studies, to demonstrate the decrease in GAD immunoreactivity that accompanies monocular deprivation, preferentially binds this smaller GAD protein. Becausc of this, it is unlikely that changes in the remaining $67-\mathrm{kDa}$ protein would be solely responsible for the decrease in GAD immunoreactivity. However, 2 other GAD mRNAs have been identified that may represent alternative splicing products or additional GAD-encoding genes, and these could be differentially regulated (Bond et al., 1988; Benson et al., 1989a).

Finally, a very small change in GAD mRNA levels that could only be revealed by rigorously counting individual grains over cells might be undetected by the methods utilized in the present study. This change would be significant if only a small portion of the total pool of GAD mRNA was accessible for translation. The fact that relatively small changes occur in only a proportion of visual cortical cells may also underlie the difficulty in detecting changes in mRNA levels of both GAD and CaM II kinase by $S 1$ nuclease protection.

\section{Conclusions}

Immunocytochemistry and receptor-binding studies have revealed that levels of a large number of neuroactive molecules are regulated in the visual cortex in an activity-dependent manner (see introductory remarks). These are probably manifestations of a more general effect whereby neural activity regulates transmitter-, receptor-, and second-messenger-related function throughout the nervous system. The present results suggest that the regulatory mechanisms involved may be complex and varied, and that activity-dependent changes may be effected at both transcriptional and posttranscriptional levels. It cannot necessarily be assumed that changes in levels of a particular protein associated with changes in neural activity are attributable to changes in transcription of the gene(s) for that protein. Many of the various potential mechanisms have been discussed above, and it is probably the interplay between these mechanisms that holds the key to understanding how neural activity regulates this aspect of neuronal function.

\section{References}

Bennett MK, Kennedy MB (1987) Deduced primary structure of the $\beta$ subunit of brain type II $\mathrm{Ca}^{2+} /$ calmodulin-dependent protein kinase determined by molecular cloning. Proc Natl Acad Sci USA 84:1794 1798.

Bennett MK, Erondu NE, Kennedy MB (1983) Purification and characterization of a calmodulin-dependent protein kinase that is highly concentrated in brain. J Biol Chem 258:12735-12744.

Benson DL, Isackson PJ, Tobin AJ, Jones EG (1988) Regulation of glutamic acid decarboxylase in the cerebral cortex. Soc Neurosci Abstr 14:347.

Benson DL, Isackson PJ, Hendry SHC, Jones EG (1989a) Expression of glutamic acid decarboxylase mRNA in normal and monocularly deprived cat visual cortex. Mol Brain Res 5:279-287.

Benson DL, Isackson PJ, Jones EG (1989b) Activity dependent gene expression in visual cortex neurons of adult monkeys. Soc Neurosci Abstr 15:843.

Benyon RJ (1980) Protein modification and the control of intracellular protein degradation. In: The enzymology of post-translational modification of proteins (Freedman RF, Hawkins HC, eds), pp 363-389. New York: Academic.

Berk AJ, Sharp PA (1977) Sizing and mapping of early adenovirus mRNAs by gel electrophoresis of S1 endonuclease-digested hybrids. Cell 12:721-732.

Black IB, Chikaraishi DM, Lewis EJ (1985) Trans-synaptic increase in RNA coding for tyrosine hydroxylase in a rat sympathetic ganglion. Brain Res 339:151-153.

Blakemore C, Garey LJ, Vital-Durant F (1978) The physiological effects of monocular deprivation and their reversal in the monkey's visual cortex. J Physiol (Lond) 283:223-262.

Bond RW, Jansen KR, Gottlieb DJ (1988) Pattern of expression of glutamic acid decarboxylase $m R N A$ in the developing rat brain. Proc Natl Acad Sci USA 85:3231-3234.

Bossa R, Martini F, Barra D, Borri Voltattorni C, Minelli A, Turano C (1977) The chymotryptic phosphopyridoxyl peptide of dopa decarboxylase from pig kidney. Biochem Biophys Res Commun 78: 177-184.

Bulleit RF, Bennett MK, Malloy SS, Hurley JB, Kennedy MB (1988) Conserved and variable regions in the subunits of brain type II $\mathrm{Ca}^{2+} /$ calmodulin-dependent protein kinase. Neuron 1:63-72.

Burgin KE, Waxham MN, Rickling S, Westgate SA, Mobley WC, Kelly PT (1990) In situ hybridization histochemistry of $\mathrm{Ca}^{2+} /$ calmodulindependent protein kinase in developing rat brain. J Neurosci 10:17881798.

Chirgwin JM, Przbyla AE, MacDonald RJ, Rutter WJ (1979) Isolation of biologically active ribonucleic acid from sources enriched in ribonuclease. Biochemistry 18:5294-5299.

Cole AJ, Saffen DW, Baraban JM, Worley PF (1989) Rapid increase of an immediate early gene messenger RNA in hippocampal neurons by NMDA receptor activation. Nature 340:474-476.

Erondu NE, Kennedy MB (1985) Regional distribution of type II $\mathrm{Ca}^{2+} /$ calmodulin-dependent protein kinase in rat brain. J Neurosci 5:32703277.

Fitzpatrick D, Lund JS, Schmechel DE, Towles AC (1987) Distribution of GABAergic neurons and axon terminals in the macaque striate cortex. J Comp Neurol 264:73-91.

Gall CM, Isackson PJ (1989) Limbic seizures increase neuronal production of messenger RNA for nerve-growth factor. Science 245:758761.

Gall C, Lauterborn J, Isackson P, White J (1990) Seizures, neuropeptide regulation, and mRNA expression in the hippocampus. In: Progress in brain research 83 (Ottersen O-P, Storm-Mathisen J, Zimmer J, eds), pp 371-390. New York: Elsevier.

Greenberg ME, Greene LA, Ziff EB (1985) Nerve growth factor and epidermal growth factor induce rapid transient changes in proto-oncogene transcription in PC12 cells. J Biol Chem 260:14101-14110.

Harris WA (1981) Neural activity and development. Annu Rev Physiol 43:689-710.

Hendrickson AE, Hunt SP, Wu J-Y (1981) Immunocytochemical lo- 
calization of glutamic acid decarboxylase in monkey striate cortex. Nature 292:605-607.

Hendry SHC, Jones EG (1986) Reduction in number of immunostained GABAergic neurons in deprived-eye dominance columns of monkey area 17 . Nature 320:750-753.

Hendry SHC, Jones EG (1988) Activity dependent regulation of GABA expression in the visual cortex of adult monkeys. Neuron 1:701-712.

Hendry SHC, Kennedy MB (1986) Immunoreactivity for a calmodulin-dependent protein kinase is selectively increased in macaque striate cortex after monocular deprivation. Proc Natl Acad Sci USA 83:1536-1540.

Hendry SHC, Schwark HD, Jones EG, Yan J (1987) Numbers and proportions of GABA immunoreactive neurons in different areas of monkey cerebral cortex. J Neurosci 7:1503-1519.

Hendry SHC, Jones EG, Burstein N (1988) Activity-dependent regulation of tachykinin-like immunoreactivity in neurons of monkey visual cortex. J Neurosci 8:1225-1238.

Hendry SHC, Fuchs J, DeBlas AL, Jones EG (1990) Distribution and plasticity of immunocytochemically localized $\mathrm{GABA}_{\mathrm{A}}$ receptors in adult monkey visual cortex. J Neurosci 10:2438-2450.

Horton JC (1984) Cytochrome oxidase patches: a new cytoarchitectonic feature of monkey visual cortex. Philos Trans R Soc Lond [Biol] 304:199-253.

Horton JC, Hubel DH (1981) Regular patchy distribution of cytochrome oxidase staining in primary visual cortex of macaque monkey. Nature 292:762-764.

Houser CR, Miyashiro JE, Kaufman DL, Tobin AJ (1989) Immunocytochemical studies using a new antiserum against bacterially produced feline glutamate decarboxylase. Soc Neurosci Abstr 15:488.

Hubel DH, Wiesel TN (1977) Functional architecture of macaque monkey visual cortex. Proc R Soc Lond [Biol] 198:1-59.

Hubel DH, Wiesel TN, LeVay S (1977) Plasticity of ocular dominance columns in monkey striate cortex. Philos Trans R Soc Lond [Biol] 278:377-409.

Kanamatsu T, Obie J, Grimes L, McGinty JF, Yoshikawa K, Sabol S, Hong JS (1986a) Kainic acid alters the metabolism of Met $^{5}$-enkephalin and the level of dynorphin $A$ in the rat hippocampus. $J$ Neurosci 6:3094-3102.

Kanamatsu T, Unsworth CD, Diliberto EJ Jr, Viveros OH, Hong JS (1986b) Reflex splanchnic nerve stimulation increases levels of proenkephalin A mRNA and proenkephalin A-related peptides in the rat adrenal medulla. Proc Natl Acad Sci USA 83:9245-9249.

Kaufman DL, Houser CR, Tobin AJ (1989) Two forms of glutamate decarboxylase (GAD), with different $\mathrm{N}$-terminal sequences, have distinct intraneuronal distributions. Soc Neurosci Abstr 15:487.

Kelly PT, McGuinness TL, Greengard P (1984) Evidence that the major postsynaptic density protein is a component of a $\mathrm{Ca}^{++} / \mathrm{cal}-$ modulin dependent protein kinase. Proc Natl Acad Sci USA 81:945949.

Kennedy MB, Bennett MK, Erondu NE (1983) Biochemical and immunochemical evidence that the "major postsynaptic density protein" is a subunit of a calmodulin-dependent protein kinase. Proc Natl Acad Sci USA 80:7357-7361.

Kessler JA, Black IB (1982) Regulation of substance P in adult rat sympathetic ganglia. Brain Res 234:182-187.

Kilpatrick DL, Howells RD, Fleminger G, Udenfriend S (1984) Denervation of rat adrenal glands markedly increases preproenkephalin mRNA. Proc Natl Acad Sci USA 81:7221-7223.

Klausner RD, Harford JB (1989) Cis-trans models for post-transcriptional gene regulation. Science 246:870-872.

Kobayashi Y, Kaufman DL, Tobin AJ (1987) Glutamic acid decarboxylase cDNA: nucleotide sequence encoding an enzymatically active fusion protein. J Neurosci 7:2769-2772.

Kujubu DA, Lim RW, Varnum BC, Herschman HR (1987) Induction of transiently expressed genes in PC12 pheochromocytoma cells. Oncogene 1:257-262.

LaGamma EF, Black IB (1989) Transcriptional control of adrenal catecholamine and opiate peptide transmitter genes. Mol Brain Res 5:17-22.

LaGamma EF, Adler JE, Black IB (1984) Impulse activity differentially regulates [Leu] enkephalin and catecholamine characters in the adrenal medulla. Science 224:1102-1104.

LeVay S, Wiesel TN, Hubel DH (1980) The development of ocular dominance columns in normal and visually deprived monkeys. $J$ Comp Neurol 191:1-51.
Lin CR, Kapiloff MS, Durgerain S, Tatemoto K, Russo AF, Hanson P, Schulman H, Rosenfeld MG (1987) Molecular cloning of a brainspecific calcium/calmodulin-dependent protein kinase. Proc Natl Acad Sci USA 84:5962-5966.

Llinás R, McGuinness TL, Leonard CS, Sugimori M, Greengard P (1985) Intraterminal injection of synapsin I or calcium/calmodulindependent protein kinase II alters neurotransmitter release at the squid giant synapse. Proc Natl Acad Sci USA 82:3035-3039.

Malenka RC, Kauer JA, Perkel DJ, Mauk MD, Kelly PT, Nicoll RA, Waxham MN (1989) An essential role for postsynaptic calmodulin and protein kinase activity in long-term potentiation. Nature 340 554-557.

Malinow R, Schulman H, Tsien RW (1989) Inhibition of postsynaptic PKC or CaMKII blocks induction but not expression of LTP. Science 245:862-866.

Malpeli JG, Schiller PH (1979) A method of reversible inactivation of small regions of brain tissue. J Neurosci Meth 1:143-151.

McGuinness TL, Brady ST, Gruner JA, Sugimori M, Llinás R, Greengard $P$ (1989) Phosphorylation-dependent inhibition by synapsin I of organelle movement in squid axoplasm. J Neurosci 9:4138-4149.

Milbrandt J (1987) A nerve growth factor-induced gene encodes a possible transcriptional regulatory factor. Science 238:797-799.

Miller SG, Kennedy MB (1985) Distinct forebrain and cerebellar isozymes of type II $\mathrm{Ca}^{2+} /$ calmodulin-dependent protein kinase associate differently with the postsynaptic density fraction. J Biol Chem 260: 9039-9046.

Miller SG, Kennedy MB (1986) Regulation of brain type II Ca ${ }^{2+}$ calmodulin-dependent protein kinase by autophosphorylation: a calcium-triggered molecular switch. Cell 44:861-870.

Miller SG, Patton BL, Kennedy MB (1988) Sequences of autophosphorylation sites in neuronal type II CaM kinase that control $\mathrm{Ca}^{2+}$. independent activity. Neuron 1:593-604.

Milner RJ, Sutcliffe JG (1983) Gene expression in rat brain. Nucleic Acids Res 11:5497-5520.

Morgan JI, Curran T (1986) Role of ion flux in the control of c-fos expression. Nature 322:552-555.

Morgan JI, Cohen DR, Hempstead JL, Curran T (1987) Mapping patterns of c-fos expression in the central nervous system after seizure. Science 237:192-197.

Morris BJ, Moneta ME, Bruggencate G, ten, Hollt V (1987) Levels of prodynorphin mRNA in rat dentate gyrus are decreased during hippocampal kindling. Neurosci Lett 80:298-302.

Pearson RB, Woodgett JR, Cohen P, Kemp BE (1985) Substrate specificity of a multifunctional calmodulin-dependent protein kinase. $J$ Biol Chem 260:14471-14476.

Peters A, Palay SL, Webster HD (1976) The fine structure of the nervous system: the neurons and supporting cells. Philadelphia: Saunders.

Roach A, Adler JE, Black IB (1987) Depolarizing influences regulate preprotachykinin mRNA in sympathetic neurons. Proc Natl Acad Sci USA 84:5078-5081.

Saffen DW, Cole AJ, Worley PF, Christy BA, Ryder K, Baraban JM (1988) Convulsant-induced increase in transcription factor messenger RNAs in rat brain. Proc Natl Acad Sci USA 85:7795-7799.

Sagar SM, Sharp FR, Curran T (1988) Expression of c-fos protein in brain: metabolic mapping at the cellular level. Science 240:13281331.

Saiki RK, Scharf S, Faloona F, Mullis KB, Horn GT, Erlich HA, Arnheim $N$ (1985) Enzymatic amplification of $\beta$-globin genomic sequences and restriction site analysis for diagnosis of sickle cell anemia. Science 230:1350-1354.

Saiki RK, Gelfand DH, Stoffel S, Scharf SJ, Higuchi R, Horn GT, Mullis KB, Erlich HA (1988) Primer directed enzymatic amplification of DNA with a thermostable DNA polymerase. Science 239:487-491.

Sanger F, Nicklen S, Coulson AR (1977) DNA sequencing with chain terminating inhibitors. Proc Natl Acad Sci USA 74:5463-5467.

Schulman H (1984) Phosphorylation of microtubule-associated proteins by a $\mathrm{Ca}^{2+} /$ calmodulin-dependent protein kinase. J Cell Biol 99: 11-19.

Steward O (1983) Alterations in polyribosomes associated with dendritic spines during reinnervation of the dentate gyrus of the adult rat. J Neurosci 3:177-188.

Sutcliffe JG, Milner RJ, Shinnick TM, Bloom FE (1983) Identifying the protein products of brain specific genes with antibodies to chemically synthesized peptides. Cell 33:671-682. 
Tabor S, Richardson CC (1987) DNA sequence analysis with a modified bacteriophage T7 DNA polymerase. Proc Natl Acad Sci USA $84: 4767-4771$.

Vulliet PR, Woodgett JR, Cohen P (1984) Phosphorylation of tyrosine hydroxylase by calmodulin-dependent multiprotein kinase. J Biol Chem 259:13680-13683.

White JD, Gall CM (1987) Differential regulation of neuropeptide and proto-oncogene mRNA content in the hippocampus following recurrent seizures. Mol Brain Res 3:21-29.

White JD, Gall CM, McKelvy JF (1987) Enkephalin biosynthesis and enkephalin gene expression are increased in hippocampal mossy fibers following a unilateral lesion of the hilus. J Neurosci 7:753-759.
Wong-Riley MTT (1979) Changes in the visual system of monocularly sutured or enucleated kittens demonstrable with cytochrome oxidase histochemistry. Brain Res 171:11-28.

Wong-Riley M, Carroll EW (1984) Effect of impulse blockade on cytochrome oxidase activity in monkey visual system. Nature 307: 262-264.

Yamauchi T, Fujisawa H (1983) Purification and characterization of the brain calmodulin-dependent protein kinase (kinase II), which is involved in the activation of tryptophan 5-monooxygenase. Eur $\mathrm{J}$ Biochem 132:15-21. 